\title{
Human Contribution to the Increasing Summer Precipitation in Central Asia from 1961 to 2013
}

\author{
DONGDONG PENG
}

State Key Laboratory of Numerical Modeling for Atmospheric Sciences and Geophysical Fluid Dynamics (LASG), Institute of Atmospheric Physics, Chinese Academy of Sciences, Beijing, Institute of Tropical and Marine Meteorology, China Meteorological Administration, Guangzhou, and University of Chinese Academy of Sciences, Beijing, China

\section{TIANJUN ZHOU}

State Key Laboratory of Numerical Modeling for Atmospheric Sciences and Geophysical Fluid Dynamics (LASG), Institute of Atmospheric Physics, Chinese Academy of Sciences, and University of Chinese Academy of Sciences, Beijing, China

\section{LIXIA ZHANG}

State Key Laboratory of Numerical Modeling for Atmospheric Sciences and Geophysical Fluid Dynamics (LASG), Institute of Atmospheric Physics, Chinese Academy of Sciences, Beijing, and Collaborative Innovation Center on Forecast and Evaluation of Meteorological Disasters, Nanjing University of Information Science and Technology, Nanjing, China

\section{Bo Wu}

\begin{abstract}
State Key Laboratory of Numerical Modeling for Atmospheric Sciences and Geophysical Fluid Dynamics (LASG),
\end{abstract} Institute of Atmospheric Physics, Chinese Academy of Sciences, Beijing, China

(Manuscript received 11 December 2017, in final form 10 July 2018)

\begin{abstract}
The ecosystem and societal development over arid Central Asia, the core connecting region of the Silk Road Economic Belt, are highly sensitive to climate change. The results derived from multiobservational datasets show that summer precipitation over Central Asia has significantly increased by $20.78 \%$ from 1961 to 2013. It remains unclear whether anthropogenic forcing has contributed to the summer wetting trend or not. In this study, the corresponding physical processes and contributions of anthropogenic forcing are investigated by comparing reanalysis and experiments of the Community Atmosphere Model, version 5.1 (CAM5.1), from the CLIVAR Climate of the Twentieth Century Plus (C20C+) Project. The observed wetting trend is well reproduced in the simulation driven by all radiative forcings (CAM5-All), but poorly reproduced in the simulation with natural forcings only (CAM5-Nat), confirming the important role of human contribution in the observed wetting trend. Moisture budget analysis shows that the observed wetting trend is dominated by the increasing vertical moisture advection term and results from enhanced vertical motion over nearly all of Central Asia. The observed contributions of moisture budget components to the wetting trend are only captured by CAM5-All experiments. The dynamic contribution is determined by the warm advection anomalies in association with a human-induced meridional uneven warm pattern. Human-induced warming increases the specific humidity over all of Central Asia, increasing (decreasing) the precipitation over the climatological ascent (descent) region in eastern (western) Central Asia.
\end{abstract}

\section{Introduction}

Precipitation is one of the most important components of the global water cycle, and its changes can deeply affect the sustainable development of economies

Corresponding author: Dr. Tianjun Zhou, zhoutj@lasg.iap.ac.cn and societies (Gillett et al. 2004). During the past half century, precipitation has experienced great changes on both global and regional scales (IPCC 2013). An accurate attribution of the changes in precipitation to specific factors is of great importance to social and scientific communities. Because of the uncertainties of climate models in simulating regional precipitation and the large 
contribution of internal variability, regional precipitation attribution is a great challenge (Gillett et al. 2004; Stott et al. 2010; Hegerl and Zwiers 2011; Sarojini et al. 2016).

Attribution studies rely greatly on the performance of model simulations (Hegerl and Zwiers 2011). Observed precipitation changes are more difficult to capture than temperature in climate models, resulting in challenges in precipitation change attribution (Hegerl and Zwiers 2011; Sarojini et al. 2016). Attribution studies on precipitation first focus on changes at the global scale and have successfully detected the influence of natural volcanic forcing (Allen and Ingram 2002; Gillett et al. 2004; Lambert et al. 2004) and anthropogenic forcing (Zhang et al. 2007; Min et al. 2011; Noake et al. 2012; Polson et al. 2013; Zhang et al. 2013). At the regional scale, the influence of human activities on precipitation changes is detected in certain specific regions, such as the high-latitude land area (Min et al. 2008; Wan et al. 2015), northern Europe (Bhend and Von Storch 2008), South Asia (Bollasina et al. 2011), southwest Australia (Delworth and Zeng 2014), and East Asia (Ma et al. 2017b).

Central Asia $\left(31^{\circ}-50^{\circ} \mathrm{N}, 60^{\circ}-95^{\circ} \mathrm{E}\right)$ is a key connecting region of the Silk Road Economic Belt extending from Asia to Europe. As an arid region, the development of society and economy in Central Asia is more sensitive to climate change than in the humid regions (Huang et al. 2016, 2017). At the interannual time scale, the precipitation variation over Central Asia is associated with the meridional displacement of the Asian subtropical westerly jet, which can be linked with the Indian summer monsoon through the South Asian high (Huang et al. 2015a; Wei et al. 2017). The interannual circumglobal teleconnection in the Northern Hemisphere summer (Ding and Wang 2005; Huang et al. 2015a,b) and El NiñoSouthern Oscillation (Mariotti 2007; Hu et al. 2017) can also modulate the precipitation variation over Central Asia. In recent decades, the climate in the eastern part of Central Asia (i.e., northwest China) has shifted from warm and dry to warm and wet (Shi et al. 2007), while the information on climate change in the western part of Central Asia is quite limited because of few stations. Many studies focus on the period 1961-2010 to address the increasing trend of precipitation in the eastern part of Central Asia based on the station data, showing that the increasing trend is mainly in summer and influenced by the changes in both specific humidity and atmospheric circulation (Zhou and Huang 2010; Zhao et al. 2014; Li et al. 2016; Peng and Zhou 2017).

However, whether the wetting trend is a result of natural or anthropogenic change and what the corresponding dynamical processes are remain unknown. Based on multiobservations, we found that the wetting trend during the past 50 years can be extended to all of
Central Asia, with the increasing trend of precipitation mainly concentrated in summer (the wet season in Central Asia). Therefore, in this study, the detection and attribution studies are applied to the increasing summer precipitation over Central Asia based on multidatasets of observations and the Community Atmosphere Model, version 5.1 (CAM5.1), simulations from the CLIVAR Climate of the Twentieth Century Plus $(\mathrm{C} 20 \mathrm{C}+)$ Detection and Attribution Project (Folland et al. 2014; Angélil et al. 2017). We show evidence that anthropogenic forcing plays an important role in the wetting trend over Central Asia.

The remainder of this paper is organized as follows. We introduce the datasets and methods in section 2. In section 3, we first detect the influence of anthropogenic forcing on the increasing precipitation over Central Asia, and then address the corresponding dynamic mechanisms responsible for the wetting trend by using a moisture budget analysis. In section 4 , the main results are summarized.

\section{Data and methods}

\section{a. Data description}

Three observed gridded monthly mean precipitation datasets and the station precipitation data covering Central Asia were used in this study:

(i) NOAA's precipitation reconstruction over land (PRECL) at a horizontal resolution of $1^{\circ} \times 1^{\circ}$, which covers the period from January 1948 to the present (Chen et al. 2002), available from https://www.esrl. noaa.gov/psd/data/gridded/data.precl.html. PRECL (Chen et al. 2002) is derived from the interpolation of gauge stations collected in the Global Historical Climatology Network, version 2 (GHCN v2), and the Climate Anomaly Monitoring System (CAMS) datasets.

(ii) The Global Precipitation Climatology Centre (GPCC) full data reanalysis, version 7.0, at a horizontal resolution of $0.5^{\circ} \times 0.5^{\circ}$ (Schneider et al. 2015), which covers the period from 1901 to 2013 and is derived from the quality-controlled worldwide stations [including GHCN v2, stations base for Climatic Research Unit (CRU), FAO, and 190 countries' stations from National Meteorological and/or Hydrological Services (NMHSs)] with record durations not less than 10 years. The data can be downloaded from ftp://ftp.dwd.de/pub/data/ gpcc/html/fulldata_v7_doi_download.html.

(iii) The monthly precipitation dataset from the University of East Anglia CRU, version 4.00 (Harris and Jones 2017), at a horizontal resolution of $0.5^{\circ} \times 0.5^{\circ}$, which 
TABLE 1. Details of the CAM5.1 simulation in the CLIVAR C20C+ Detection and Attribution Project.

\begin{tabular}{lll}
\hline \hline Experiment information & \multicolumn{1}{c}{ CAM5-All } & CAM5-Nat \\
\hline Period & January 1959-June 2015 & January 1959-June 2015 \\
No. of members & 50 & 50 \\
Greenhouse gases & As observed & Preindustrial \\
Sea surface & As observed & Anthropogenic attributable parts are subtracted \\
Sea ice & As observed & Anthropogenic attributable parts are subtracted \\
Tropospheric aerosols & As observed & Preindustrial \\
Volcanic aerosols & As observed & As observed \\
Solar irradiance & As observed & As observed \\
Land cover & As observed & Preindustrial \\
Stratospheric zone & As observed & Preindustrial \\
\hline
\end{tabular}

covers the period from 1901 to 2015 and is derived from the interpolation of worldwide stations. The dataset is available from http://dx.doi.org/10.5072/ edf8febfdaad48abb2cbaf7d7e846a86. Most of the stations used in the three gridded datasets are similar.

(iv) The available monthly mean precipitation from original stations provided by both the China Meteorological Administration (CMA; http://data. cma.cn/en) and NOAA GHCN (ftp://ftp.ncdc.noaa. gov/pub/data/ghcn/) are also employed in this study to verify the observed precipitation trend derived from gridded datasets. This is because gridded precipitation datasets use the spatial interpolation to fill the missing grid boxes, which may induce large bias in the regions with sparse stations, such as Central Asia. The precipitation data from GHCN are homogeneity adjusted. The precipitation stations from CMA are homogenized by Ma et al. (2015) based on the penalized maximum $F$ test. To focus on the long-term trend, only the stations with at least $80 \%$ available records during the study period were used. In total, 75 homogenized stations (hereafter 75Station), that is, 10 stations from GHCN and 65 stations from CMA, were used.

The monthly Japanese 55-year Reanalysis (JRA-55) dataset, conducted by Japan Meteorology Agency at a horizontal resolution of $1.25^{\circ} \times 1.25^{\circ}$ and covering the period from 1958 to present, is used in this study (Kobayashi et al. 2015). The precipitation from JRA-55 is essentially a model variable and is used in this study for the moisture budget analysis.

The model experiments are from the CLIVAR $\mathrm{C} 20 \mathrm{C}+$ Detection and Attribution Project (Folland et al. 2014). The monthly mean datasets used in this study are conducted by the CAM5.1 (atmosphere-only model) at the horizontal resolution of $\sim 1^{\circ} \times 1^{\circ}$ (Stone et al. 2018). The model has two experiments, CAM5-All and CAM5-Nat, and each has 50 realizations and covers the period from January 1959 to June 2015 (Table 1). All the realizations start from the same initial state but with small uniform perturbations applied to the threedimensional temperature field. The CAM5-All, representing the "real world" scenario, is forced by observed sea surface temperature (SST) and sea ice, historical greenhouse gases, tropospheric aerosols, volcanic aerosols, solar irradiance, land cover, and stratospheric ozone. In the CAM5-Nat, which represents the "natural world" scenario, the solar irradiance and volcanic aerosols are the same as those in CAM5-All, while tropospheric aerosols, greenhouse gas, stratospheric ozone, and land cover are fixed at the estimated preindustrial level. Most importantly, the anthropogenic contributions of SST and sea ice coverage estimated from CMIP5 models using the optimal fingerprinting method are subtracted from observations (D. Stone and P. Pall 2018, unpublished manuscript) to create reasonable natural sea surface boundaries for CAM5-Nat. Thus, the difference between the ensemble mean of CAM5-All and CAM5Nat reveals the anthropogenic contribution (CAM5-Ant). For more details of the experimental design, the readers are referred to the website of the CLIVAR C20C+ Detection and Attribution Project (http://portal.nersc.gov/ c20c/main.html). The model simulations from CLIVAR $\mathrm{C} 20 \mathrm{C}+$ experiments conducted by research institutes around the world are publicly accessible from http:// portal.nersc.gov/c20c/data.html and have been widely used in climate attribution and climate change studies (e.g., Angélil et al. 2017; Ma et al. 2017a; also see the publication list at http://portal.nersc.gov/c20c/pub.html).

\section{b. Moisture budget analysis}

The commonly used vertical integral of the moisture budget equation is employed in this study to address the changes in precipitation (Seager et al. 2010; Chou and Lan 2012; Chou et al. 2013):

$$
P^{\prime}=E^{\prime}-\partial_{t}\langle q\rangle-\left\langle\mathbf{V}_{h} \cdot \nabla_{h} q\right\rangle^{\prime}-\left\langle\omega \partial_{p} q\right\rangle^{\prime}+\delta .
$$




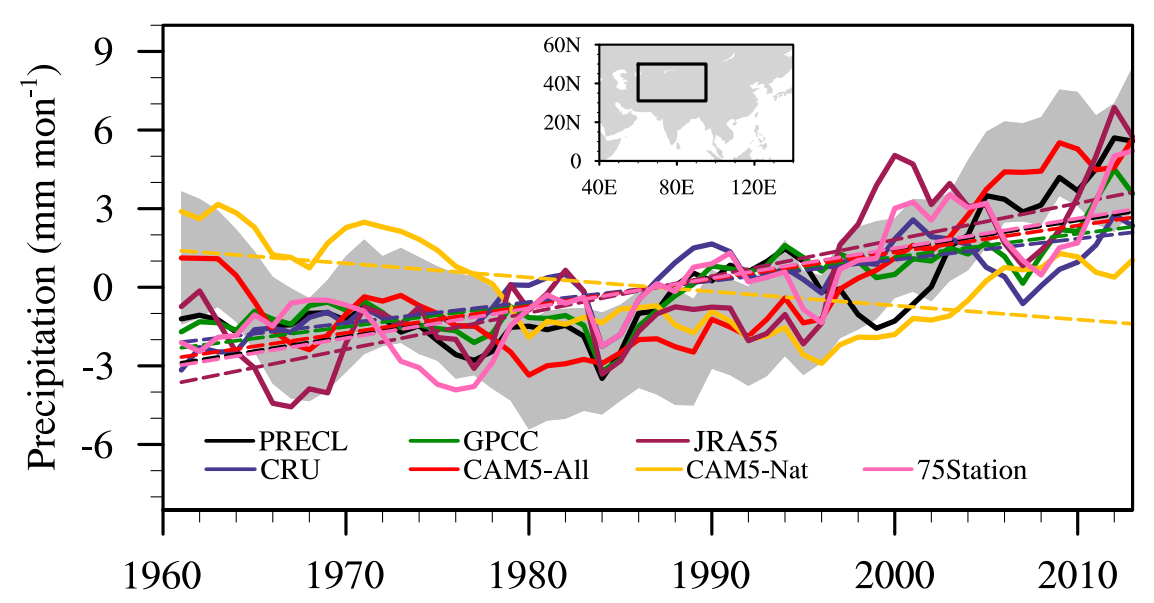

FIG. 1. The 5-yr running mean summer (June-August) mean precipitation anomalies $\left(\mathrm{mm}\right.$ month $\left.^{-1}\right)$ averaged over Central Asia $\left(60^{\circ}-95^{\circ} \mathrm{E}, 31^{\circ}-50^{\circ} \mathrm{N}\right.$; see the black box in the inset map) for 1961-2013. Four observations, namely, PRECL, GPCC, CRU, and 75Station are indicated by the black, green, blue, and hot pink lines, respectively. The violet red, red, and yellow lines are for JRA-55, the ensemble mean of CAM5-All, and CAM5-Nat, respectively. The gray shading denotes the standard deviation of the 50 members in CAM5-All. The dashed lines are the corresponding linear trends. All the trends are statistically significant at the $5 \%$ level.

Here, $P, E$, and $q$ denote precipitation, evaporation, and specific humidity, respectively. The $\mathbf{V}_{h}$ is the horizontal vector wind, $\omega$ is the vertical velocity, \langle\rangle is the column integration from the surface to tropopause, $\partial_{t}$ and $\partial_{p}$ denote the time and pressure derivative of variables, respectively, and $\nabla_{h}$ is the horizontal operator. The term $\partial_{t}\langle q\rangle$ is small and can be neglected on a seasonal scale, and $-\left\langle\mathbf{V}_{h} \cdot \nabla_{h} q\right\rangle^{\prime}$ and $-\left\langle\omega \partial_{p} q\right\rangle^{\prime}$ are the changes in horizontal and vertical advection terms, respectively. The residual term $\delta$ indicates the subseasonal transient eddies and is relatively smaller than other terms (Seager et al. 2010; Chou et al. 2013). The change ( $)^{\prime}$ denotes the departure from the long-term mean $\left(^{-}\right)$. The changes in vertical advection $-\left\langle\omega \partial_{p} q\right\rangle^{\prime}$ can be further divided into a dynamic contribution $-\left\langle\omega^{\prime} \partial_{p} \bar{q}\right\rangle$ in association with changes in atmospheric circulation, and a thermodynamic contribution $-\left\langle\bar{\omega} \partial_{p} q^{\prime}\right\rangle$ in association with changes in specific humidity, and nonlinear terms $-\left\langle\omega^{\prime} \partial_{p} q^{\prime}\right\rangle$. Thus, Eq. (1) can be further expressed as

$P^{\prime} \approx E^{\prime}-\left\langle\mathbf{V}_{h} \cdot \nabla_{h} q\right\rangle^{\prime}-\left\langle\omega^{\prime} \partial_{p} \bar{q}\right\rangle-\left\langle\bar{\omega} \partial_{p} q^{\prime}\right\rangle-\left\langle\omega^{\prime} \partial_{p} q^{\prime}\right\rangle+\delta$.

As the evaporation is not output directly in model simulations, we estimate evaporation using the equation

$$
E=L / \lambda
$$

where $L$ is the surface latent heat flux, and $\lambda$ is the latent heat of vaporization $\left(\mathrm{MJ} \mathrm{kg}^{-1}\right) ; \lambda=2.501-$ $\left(2.361 \times 10^{-3}\right) T$, where $T$ is the air temperature $\left({ }^{\circ} \mathrm{C}\right)$ (Allen et al. 1998).

\section{c. Statistical methods}

We use the Mann-Kendall nonparametric method to test the significance of long-term trends for the spatial patterns. We test the significance of linear trends for regional-averaged values using the Student's $t$ test. Both the two test methods are based on the functions from NCAR Command Language (NCL; http://www.ncl. ucar.edu/). The probability density functions are derived from nonparametric kernel estimation and a Gaussian smoother. Note the precipitation trend over Central Asia is calculated for each realization in both CAM5-All and CAM5-Nat. To test the significance of different probability density functions, we use the twosided Kolmogorov-Smirnov (KS) test based on the MATLAB software. We set the confidence level as $95 \%$ in this study.

\section{Results}

\section{a. Observed and simulated precipitation changes in Central Asia}

We first show the observed and model-simulated regional-averaged summer (June-August) precipitation anomalies in Fig. 1. Anomalies are calculated as deviations from the 1961-2013 climatology. The original (running mean) time series of summer precipitation from PRECL, GPCC, and CRU match the 75Station well, at a correlation coefficient of $0.76(0.77), 0.74(0.86)$, and 0.72 (0.84), respectively, significant at the $5 \%$ level. From 1961 to 2013, all of the four observations, namely, 75Station, PRECL, GPCC, and CRU, consistently show 
TABLE 2. Details of area-weighted regional-averaged summer precipitation in Central Asia $\left(31^{\circ}-50^{\circ} \mathrm{N}, 60^{\circ}-95^{\circ} \mathrm{E}\right)$. Bold font indicates that the trends are statistically significant at the $5 \%$ level (see methods for details).

\begin{tabular}{|c|c|c|c|c|c|c|c|}
\hline & \multirow{2}{*}{$\frac{\text { Mean }\left(\mathrm{mm} \mathrm{month}{ }^{-1}\right)}{1961-2013}$} & \multicolumn{3}{|c|}{ Trend per decade $\left(\mathrm{mm} \mathrm{month}{ }^{-1}\right.$ decade $\left.^{-1}\right)$} & \multicolumn{3}{|c|}{ Trend per decade $\left(\%\right.$ decade $\left.^{-1}\right)$} \\
\hline & & 1961-2013 & 1961-80 & 1981-2013 & 1961-2013 & 1961-80 & $1981-2013$ \\
\hline PRECL & 25.32 & 1.11 & -1.04 & 1.99 & 4.38 & -4.11 & 7.86 \\
\hline GPCC & 26.82 & 0.89 & -0.57 & 1.43 & 3.32 & -2.13 & 5.33 \\
\hline CRU & 28.24 & 0.81 & 0.78 & 0.58 & 2.87 & 2.76 & 2.05 \\
\hline 75Station & 20.63 & 1.14 & -0.97 & 1.37 & 5.53 & -4.70 & 6.64 \\
\hline Obs mean & 25.25 & 0.99 & -0.45 & 1.34 & 3.92 & -1.78 & 5.31 \\
\hline JRA-55 & 46.07 & 1.39 & -0.45 & 1.99 & 3.02 & -0.98 & 4.32 \\
\hline CAM5-All & 46.65 & 1.02 & -1.37 & 2.98 & 2.19 & -2.94 & 6.39 \\
\hline CAM5-Nat & 50.71 & -0.54 & -1.41 & 0.82 & -1.06 & -2.78 & 1.62 \\
\hline
\end{tabular}

that the summer precipitation in Central Asia has increased significantly at the $5 \%$ level, at rates of 1.14 , $1.11,0.89$, and $0.81 \mathrm{~mm} \mathrm{month}^{-1} \mathrm{decade}^{-1}$, respectively. The summer precipitation from the ensemble mean of the four datasets declines from 1961 to 1980 and increases from 1981 to 2013, with a significant increasing trend of $0.99 \mathrm{~mm} \mathrm{month}^{-1}$ decade $^{-1}$ during 1961-2013. In arid Central Asia, the climatological summer precipitation is $25.25 \mathrm{~mm}^{\text {month }}{ }^{-1}$ (Table 2); thus, the precipitation has increased significantly by $20.78 \%$ during the past 50 years $\left(3.92 \%\right.$ decade $\left.^{-1}\right)$, which is mainly from the period 1981-2013 (5.31\% decade $\left.{ }^{-1}\right)$. JRA-55 shows high performance in capturing the evolution of observed precipitation, with a correlation coefficient of 0.64 (0.65), 0.74 (0.77), $0.72(0.76)$, and $0.72(0.81)$ for the original (running mean) results from PRECL, GPCC, CRU, and 75Station, respectively, significant at the $5 \%$ level. The observed increasing precipitation during 1961-2013 is seen in the JRA-55, with a value of $1.39 \mathrm{~mm}^{\text {month }}{ }^{-1}$ decade $^{-1}$ (increased by $16.01 \%$ during the past 50 years). We note the climatological precipitation in JRA-55 is larger than the observations (Table 2).

The observed significant wetting trend during 19612013 is well captured in CAM5-All experiments with an ensemble mean value of $1.02 \mathrm{~mm} \mathrm{month}^{-1}$ decade $^{-1}$ (increased by $11.61 \%$ during the past 50 years), whereas precipitation from the ensemble mean of CAM5-Nat shows a significant drying trend at a rate of $-0.54 \mathrm{~mm} \mathrm{month}^{-1} \mathrm{decade}^{-1}$ (decreased by $5.62 \%$ during 1961-2013; Table 2).

The observed and simulated spatial patterns of the long-term trend for summer precipitation during 19612013 are shown in Fig. 2. The precipitation from $89 \%$ of the stations shows an increasing trend, with $24 \%$ of the stations significant at the $5 \%$ level, confirming the increasing summer precipitation in Central Asia (Fig. 2a). The spatial patterns of precipitation trend derived from three gridded observations (PRECL, CRU, and GPCC) are similar to that from 75 Station, consistently indicating that the wetting trend is not limited to northwestern China but extends to western Central Asia, with a significant wetting trend for the southwestern part of Central Asia (greater than $15 \%$ decade $^{-1}$ ) (Figs. $2 \mathrm{a}-\mathrm{d}$ ). The spatial pattern of precipitation trend derived from JRA-55 resembles the observations (Fig. 2e).

We compare the simulated spatial patterns of precipitation changes (Figs. 2f,g) with the observations (Figs. 2a-d). In response to the combination of both natural and anthropogenic influence, summer precipitation increases significantly over most regions of Central Asia in the ensemble mean of CAM5-All, matching the observations well, although with relatively larger wetting regions than observations over the northern part of Central Asia (Fig. 2f). The percentage change of precipitation in CAM5-All is lower than observations (Fig. 2f and Table 2). In contrast to the uniform wetting pattern in CAM5-All, a significant drying trend south of $35^{\circ} \mathrm{N}$ and weak wetting trend north of $35^{\circ} \mathrm{N}$ are seen in CAM5Nat (Fig. 2g). The difference between the ensemble mean of CAM5-All and CAM5-Nat represents the humaninduced changes, indicating that human influence contributes to a significant wetting trend in Central Asia.

We further assess the reliability of the attribution result in the following way: in each scenario (CAM5-All and CAM5-Nat), we calculate the regional-averaged precipitation trends over Central Asia from individual realizations, and then, we use the nonparametric kernel estimation with a Gaussian smoother to obtain the corresponding probability density functions (Fig. 3). The analysis conducted here is similar to the method used in Knutson et al. (2013). The probability density functions of simulated precipitation trends derived from different experiments are statistically distinguishable with the two-sided Kolmogorov-Smirnov test, indicating that the long-term changes in precipitation over Central Asia are strongly affected by human activities. The observed precipitation trends (hot pink and black circles, black triangle, and star in Fig. 3) are largely outside the distribution of the CAM5-Nat (blue line, 


\section{(a) 75Station}

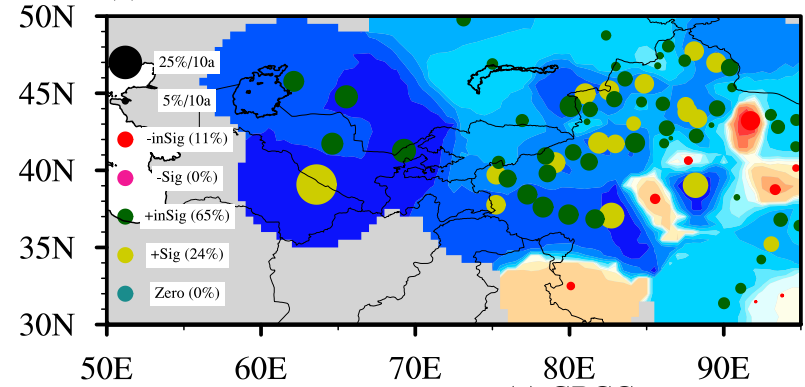

(b) PRECL

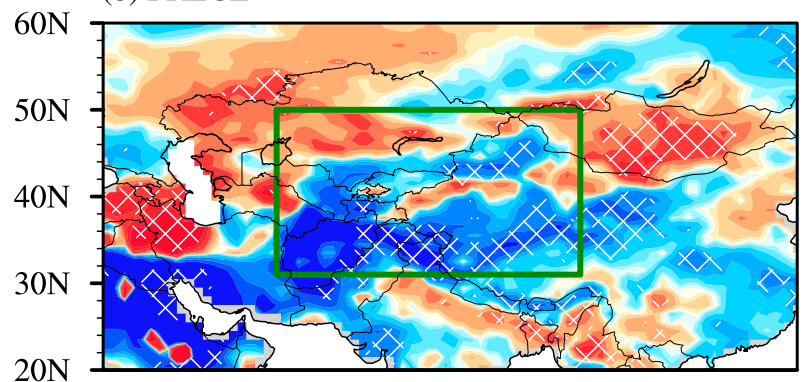

(d) CRU

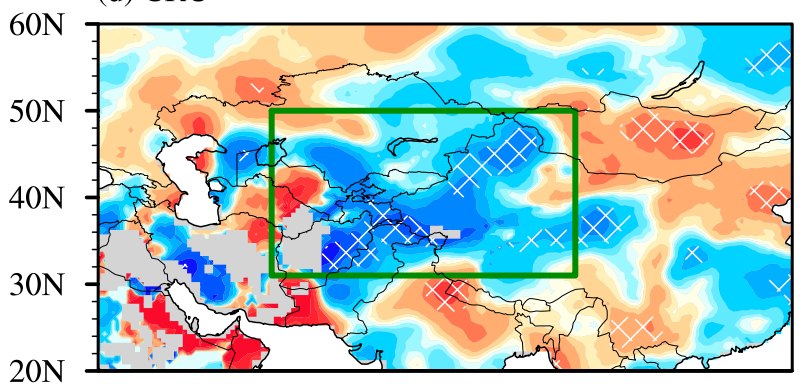

(f) CAM5-All

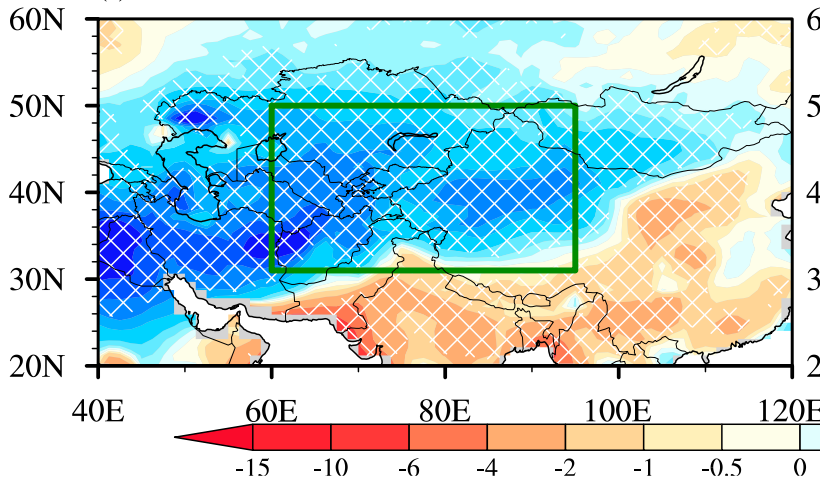

(c) GPCC

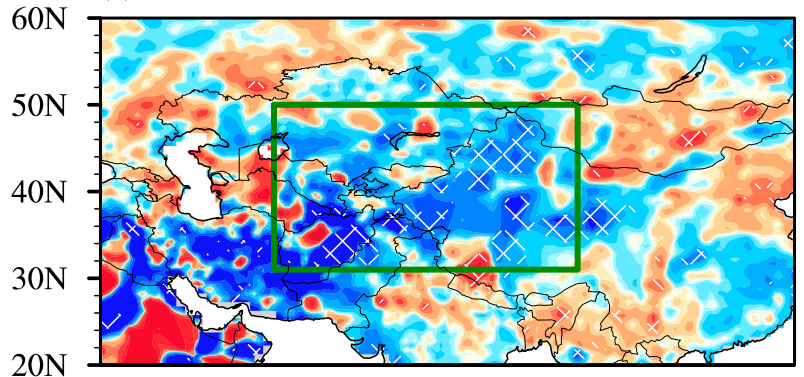

(e) JRA55

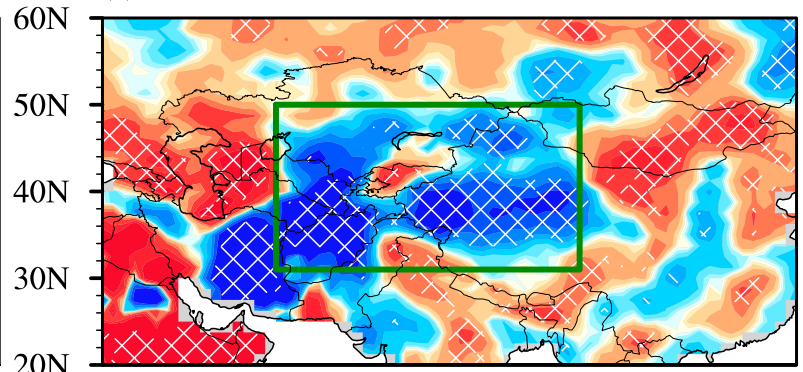

(g) CAM5-Nat

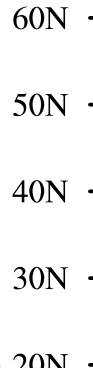

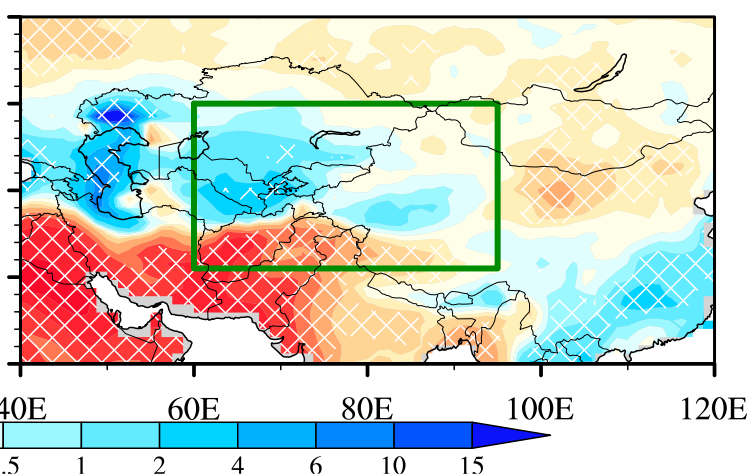

FIG. 2. Summer precipitation trends (\% decade ${ }^{-1}$ ) for 1961-2013. (a) 75Station. Dots indicate the precipitation trend from station data with the size proportional to the magnitude (see black dots and the corresponding values in the top-left corner; here $25 \% / 10$ a means $25 \%$ decade ${ }^{-1}$ ), and color shadings indicate the corresponding gridded results. Gray shading indicates the regions with missing values. The percentages of stations with significant (Sig) or insignificant (inSig) increasing $(+)$ or decreasing $(-)$ precipitation trends are shown at left. (b) PRECL; (c) GPCC; (d) CRU; (e) JRA-55; (f) CAM5-All; (g) CAM5-Nat. The white hatching indicates that trends over the regions in (b)-(g) are statistically significant at the $5 \%$ level (same in the following figures). The green box indicates the study region of Central Asia.

with $5 \%-95 \%$ uncertainty range from -1.40 to $0.38 \mathrm{~mm} \mathrm{month}^{-1}$ decade $^{-1}$ ), indicating that this wetting trend is an unusual event when compared with results in a natural world (driven with only natural forcing). In contrast, all the observed trends are concentrated in the distribution from the CAM5-All (Fig. 3, red line, with 5\%$95 \%$ uncertainty range of $0.42-1.64 \mathrm{~mm} \mathrm{month}^{-1} \mathrm{decade}^{-1}$ ), demonstrating the significant contribution of human 


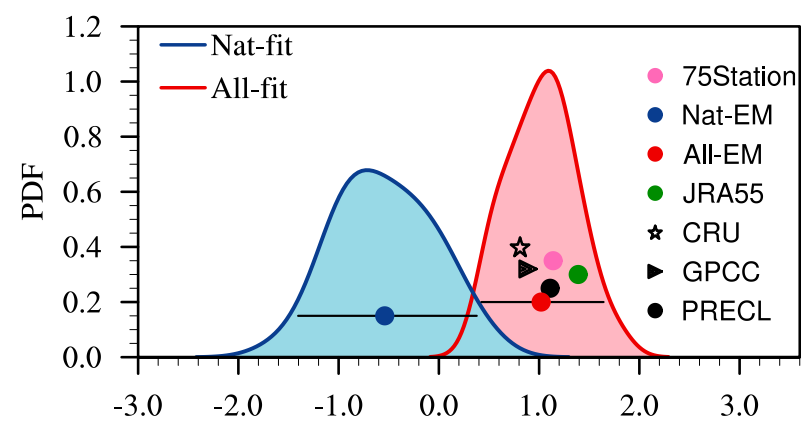

FIG. 3. The probability density functions of precipitation trends $\left(\mathrm{mm}\right.$ month $^{-1}$ decade $^{-1}$ ) from CAM5-All (red line) and CAM5Nat (blue line). The black triangle and star denote the trends from GPCC and CRU, respectively. The black and hot pink circles denote the trends from PRECL and 75Station, respectively. The green, red, and blue circles denote the trends from JRA-55, CAM5All (All-EM), and CAM5-Nat (Nat-EM), respectively; EM indicates ensemble mean. The horizontal black lines through the two simulated values indicate a range of $5 \%-95 \%$ from the corresponding distribution.

activities to the significant wetting trend. Based on the significant precipitation trend of -0.54 (1.02) $\mathrm{mmmonth}^{-1}$ decade $^{-1}$ derived from the ensemble mean of CAM5-Nat (CAM5-All), the humaninduced summer precipitation trend is estimated to be $1.56 \mathrm{~mm} \mathrm{month}^{-1}$ decade $^{-1}$, that is, the summer precipitation over Central Asia has significantly increased by $17.72 \%$ (relative to the climatological value from CAM5All) from 1961 to 2013 in response to anthropogenic influence.

\section{b. Moisture budget analysis of the observed and simulated wetting trend}

To understand the physical mechanisms responsible for the human-induced wetting trend, we conduct the moisture budget analysis. For both spatial patterns (Fig. 2e) and regional-averaged perspective (Figs. 1, 3 and Table 2), the precipitation changes over Central Asia from the JRA-55 show high consistency with those from observations. Thus, the variables related to precipitation changes derived from the JRA-55 data are used in the following analysis.

The trends of regional-averaged moisture budget components over Central Asia are shown in Fig. 4. In JRA-55 (green bars), the evaporation changes coherently couple with precipitation changes, suggesting a feedback between the increasing evaporation and precipitation. The change of precipitation is larger than evaporation, indicating a net wetting trend. The linear trend of the vertical moisture advection term is $0.9 \mathrm{~mm} \mathrm{month}^{-1}$ decade $^{-1}$, playing a dominant contribution to the observed wetting trend. We further separate this term into dynamic and thermodynamic components. The linear trend of the dynamic term

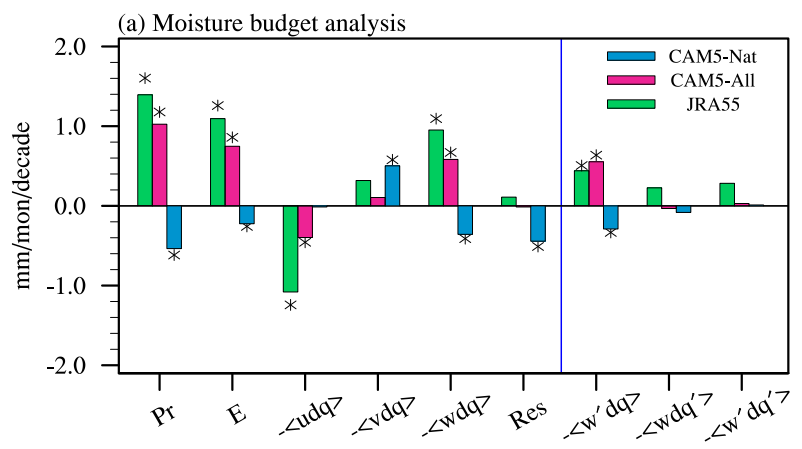

(b) Human-induced wetting trend

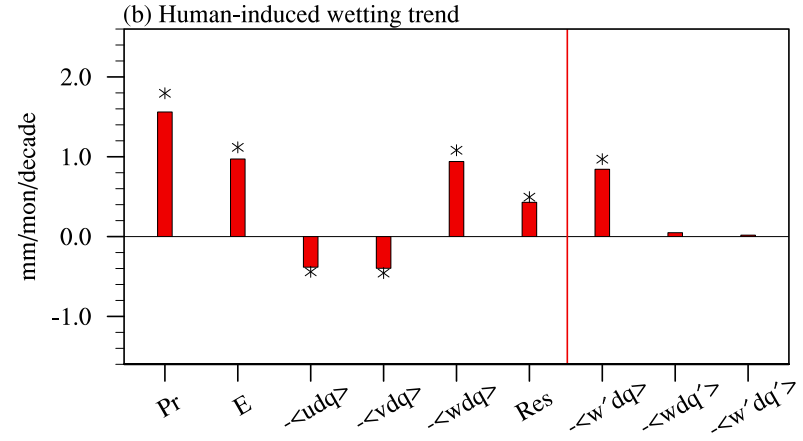

FIG. 4. Trend (mm month ${ }^{-1}$ decade $^{-1}$ ) for moisture budget components averaged over Central Asia. Pr is precipitation; $E$ is evaporation; $-\langle u d q\rangle,-\langle v d q\rangle$, and $-\langle w d q\rangle$ are the zonal, meridional, and vertical moisture advection terms, respectively; Res is the residual term; $-\left\langle w^{\prime} d q\right\rangle,-\left\langle w d q^{\prime}\right\rangle$, and $-\left\langle w^{\prime} d q^{\prime}\right\rangle$ are the dynamic, thermodynamic, and nonlinear components, respectively. (a) The results from JRA-55, CAM5-All, and CAM5-Nat are denoted by green, maroon, and blue colors, respectively; (b) the results induced by anthropogenic forcing. Black stars indicate that the trends are statistically significant at the $5 \%$ level.

(viz. the changes in atmospheric circulation) is about 3 times larger than the thermodynamic term (viz. the changes in specific humidity). The contribution of the horizontal moisture advection term is negative. The trends of moisture budget components in the ensemble mean of CAM5-All (Fig. 4, the maroon bars) are comparable with the JRA-55 except for weaker magnitude, demonstrating a reasonable representation of the physical processes associated with the wetting trend in the CAM5-All simulation. The drying trend in CAM5-Nat comes from both the vertical moisture advection and eddy terms, while the horizontal moisture advection terms increase significantly and partly offset the drying trend. The declined dynamic components contribute to the drying Central Asia in CAM5-Nat. To estimate the anthropogenic contribution, we focus on the difference between CAM5-All and CAM5-Nat (Fig. 4b). The human-induced increasing trend of precipitation is dominated by the dynamic component of vertical moisture advection.

We compare the spatial patterns for the trends of moisture budget components derived from JRA-55 and 

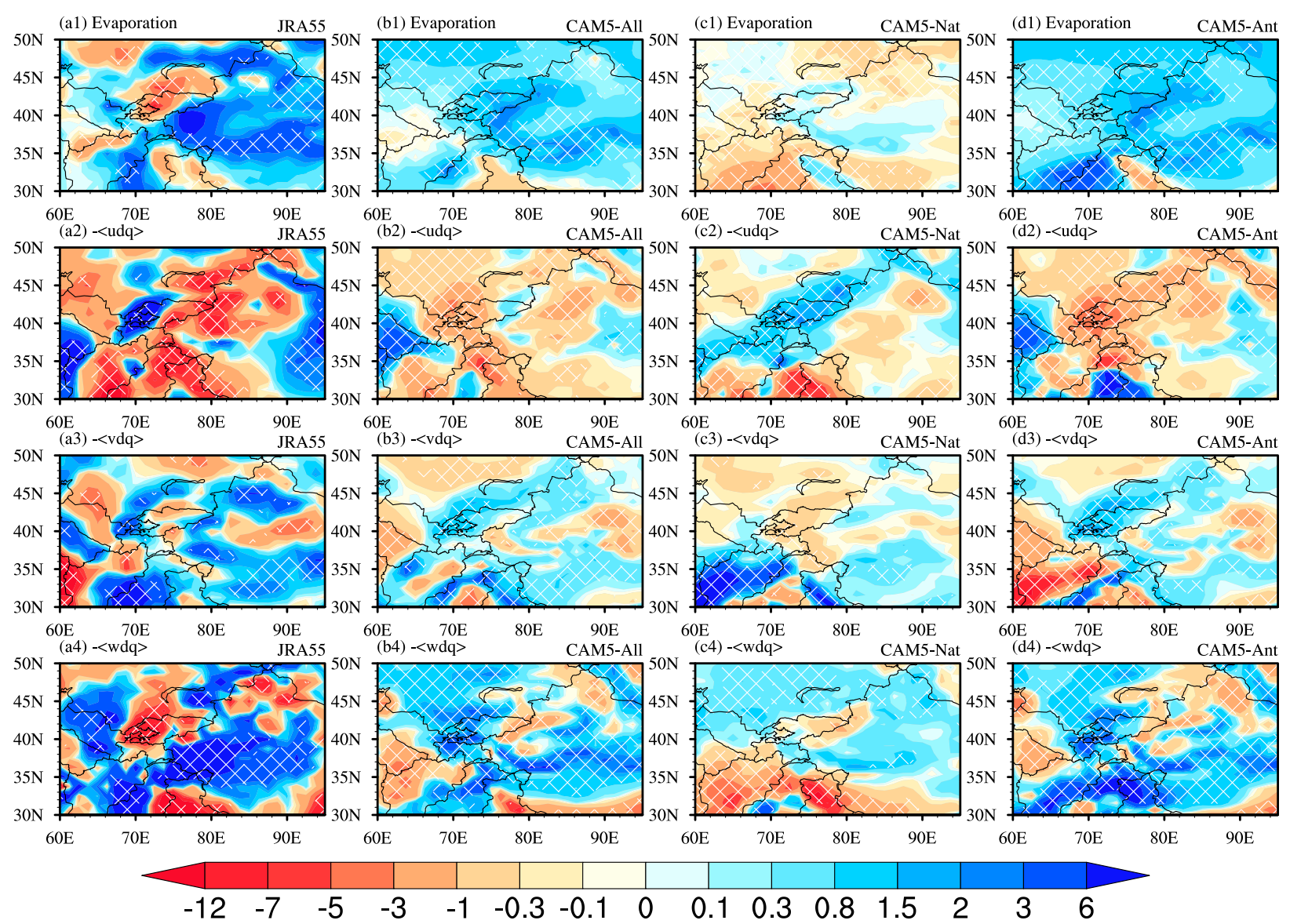

FIG. 5. Spatial patterns for the long-term trend ( $\left.\mathrm{mm} \mathrm{month}^{-1} \mathrm{decade}^{-1}\right)$ of moisture budget components. (top)-(bottom) Evaporation, zonal, meridional, and vertical moisture advection terms, respectively. (a)-(d) Results from JRA-55, CAM5-All, CAM5-Nat, and CAM5Ant, respectively.

model simulations in Fig. 5. In JRA-55 [Figs. 5a(1)-(4)], the evaporation change is also well coupled with the precipitation change and exhibits an increasing trend over Central Asia. The summer surface air temperature in Central Asia has increased significantly at a rate of $0.21^{\circ} \mathrm{C} \mathrm{decade}^{-1}$ during $1961-2013$ (Table 3), which is favorable for the evaporation process, that is, the vaporization and removal of liquid water (Allen et al. 1998). The horizontal moisture advection terms partly offset the increasing trend of precipitation, owing to the larger magnitude of negative contribution from zonal meridional moisture advection term in comparison to the positive contribution from meridional moisture advection term. The trend of vertical moisture advection term resembles that of the precipitation, demonstrating its dominant role [Fig. 5a(4)]. These processes revealed by JRA-55 are well captured by CAM5-All [Figs. 5b(1)-(4)], whereas they are absent in CAM5-Nat [Figs. 5c(1)-(4)]. The differences between CAM5-All and CAM5-Nat are regarded as the results of anthropogenic influence [Figs. 5d(1)-(4)]. Clearly, anthropogenic forcing is favorable for the observed changes in vertical moisture advection [Fig. 5d(4)], contributing to the wetting trend over Central Asia, whereas horizontal moisture advection term in response to human influence shows a decreasing trend [Fig. $5 \mathrm{~d}(2)]$. A human-induced increase of evaporation is also seen in Central Asia.

The spatial patterns for the changes in dynamic and thermodynamic components of vertical moisture advection term are further examined in Fig. 6. In JRA-55,

TABLE 3. As in Table 2, but for the summer mean surface air temperature.

\begin{tabular}{lccccc}
\hline & Mean $\left({ }^{\circ} \mathrm{C}\right)$ & & \multicolumn{2}{c}{ Trend per decade $\left({ }^{\circ} \mathrm{C}\right.$ decade $\left.{ }^{-1}\right)$} \\
\cline { 2 - 3 } \cline { 5 - 6 } & $(1961-2013)$ & & $1961-2013$ & $1961-80$ & $1981-2013$ \\
\hline JRA-55 & 18.76 & & $\mathbf{0 . 2 1}$ & 0.16 & $\mathbf{0 . 2 7}$ \\
CAM5-All & 20.66 & & $\mathbf{0 . 2 9}$ & 0.01 & $\mathbf{0 . 3 9}$ \\
CAM5-Nat & 20.45 & & $-\mathbf{0 . 0 3}$ & -0.08 & $\mathbf{0 . 0 0}$ \\
\hline
\end{tabular}


(a) $-<w^{\prime} d q>$

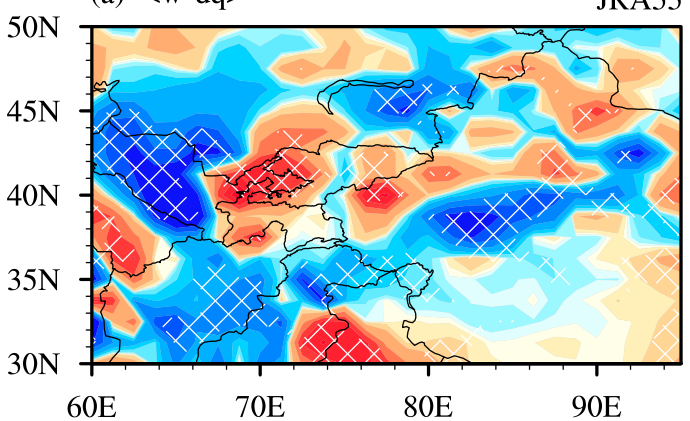

(c) $-<w^{\prime} d q>$

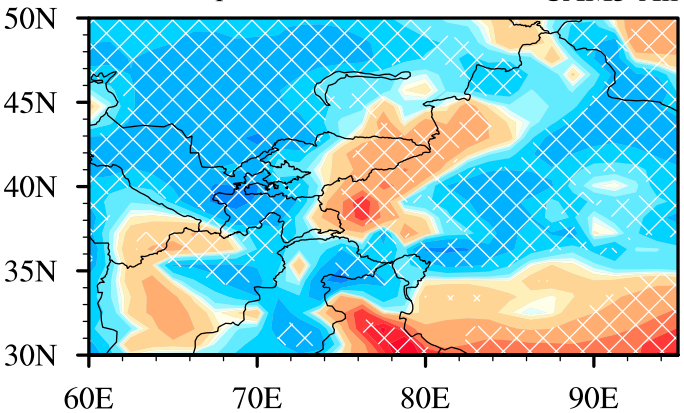

$90 \mathrm{E}$

(e) $-<w^{\prime} d q>$

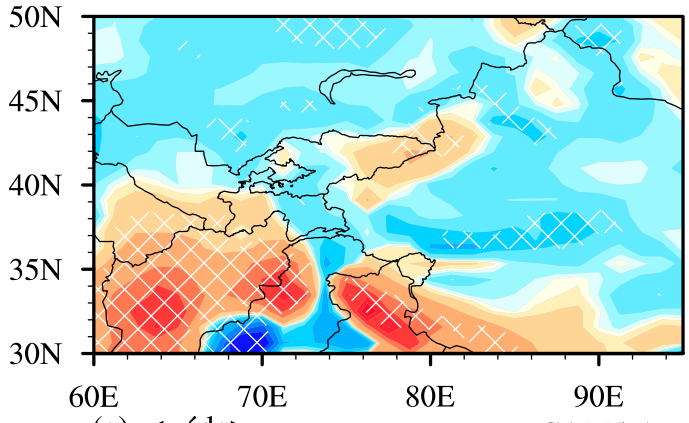

(g) $-<w^{\prime} d q>$

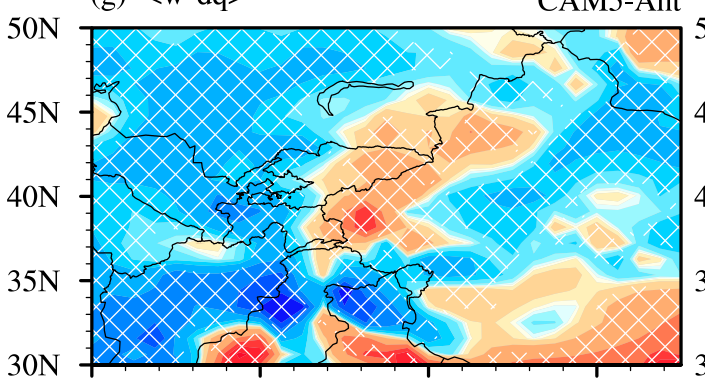

$60 \mathrm{E}$

$70 \mathrm{E}$

$80 \mathrm{E}$

$90 \mathrm{E}$
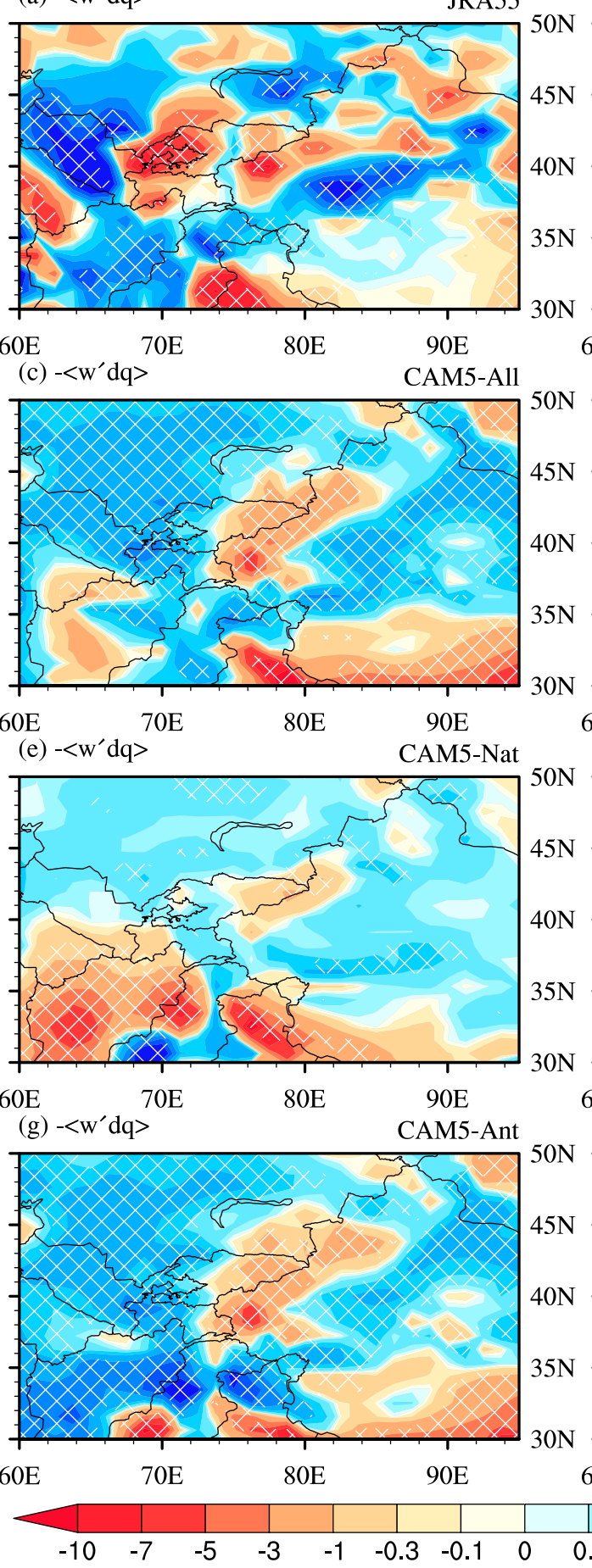

(b) $-<w d q^{\prime}>$

JRA55

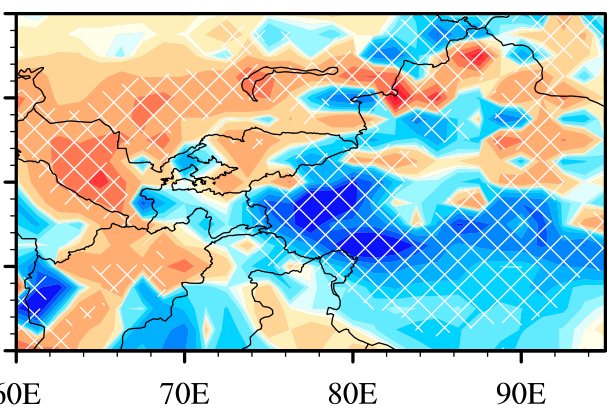

(d) $-<w d q^{\prime}>$

CAM5-All
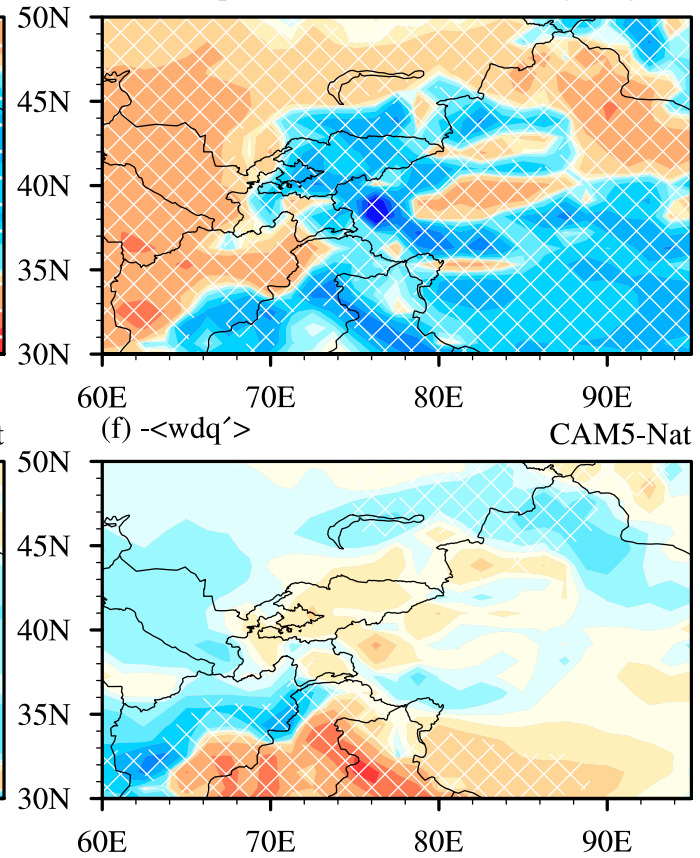

(h) $-<w d q^{\prime}>$

CAM5-Ant

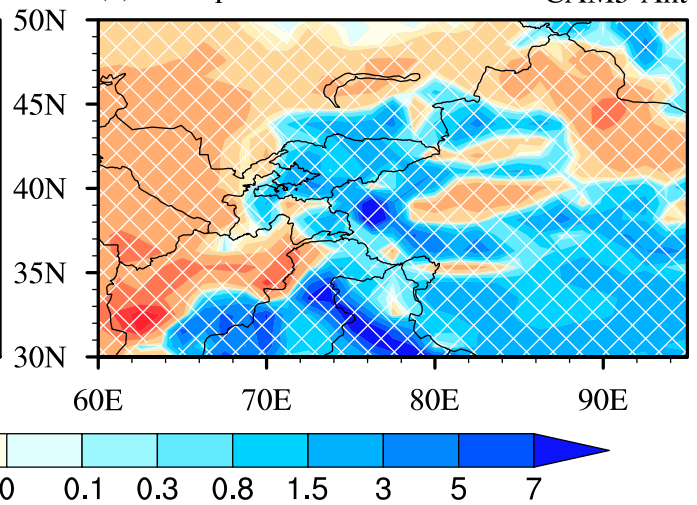

FIG. 6. Spatial patterns for the long-term trend ( $\mathrm{mm} \mathrm{month}^{-1}$ decade $^{-1}$ ) of (left) dynamic and (right) thermodynamic components of changes in vertical moisture advection term. Results from (a),(b) JRA-55, (c),(d) CAM5All, (e),(f) CAM5-Nat, and (g),(h) CAM5-Ant.

the dynamic component (Fig. 6a) shows the same trend as the vertical moisture advection [Fig. 5a(4)], with an increasing trend over the western and eastern parts of Central Asia but a decreasing trend over the middle part
(Fig. 6a). The thermodynamic term has a negative contribution to the western part but a positive contribution to the eastern part, showing a zonal dipole pattern over Central Asia (Fig. 6b). Thus, the dynamic component 
caused by anomalous vertical ascending motion has a positive contribution to the eastern and western parts of Central Asia, while the thermodynamic component mainly contributes to the wetting trend over the eastern part and partly offsets the wetting trend over the western part of Central Asia. The spatial patterns of changes in both dynamic and thermodynamic components revealed by JRA-55 data are also seen in CAM5-All (Figs. 6c,d), which provides us more confidence to reveal the physical mechanisms responsible for the wetting trend in response to anthropogenic forcing. In CAM5-Nat (Figs. 6e,f), the dynamic component has a weak increasing trend over the northern part and a strong decreasing trend over the southern part, while the thermodynamic component shows an increasing trend over western part and a decreasing trend over the eastern part. Therefore, both the thermodynamic and dynamic contributions in CAM5-All come from anthropogenic contribution (Figs. 6g,h). Based on the analysis, it is evident that the humaninduced changes in the dynamic component have increased the summer precipitation over nearly all of Central Asia. The changes in the thermodynamic component, in response to human influence, increase the summer precipitation over the eastern part but decrease the summer precipitation over the western part of Central Asia. Because of the cancelling effect of the dipole distribution pattern, the regional-averaged thermodynamic contribution in response to human influence over Central Asia is weak.

\section{c. Physical mechanisms responsible for the human-induced wetting trend}

The above results show that changes in dynamic components are important for the precipitation changes over Central Asia. A recent study by Peng and Zhou (2017) demonstrated that changes in thermodynamic components play an important role in the wetting trend over eastern Central Asia. In this section, the physical mechanisms responsible for the dynamic and thermodynamic components of moisture budget are examined.

The changes in the dynamic component are in agreement with the changes in anomalous vertical motion, based on Eq. (2). Climatologically, western and eastern Central Asia are the subsidence and ascent regions, respectively (Figs. 7a,b). During 1961-2013, an anomalous ascending motion occurs over western and eastern Central Asia and an anomalous descending motion occurs over the middle part of Central Asia (Figs. 7c,d,f), corresponding to the changes in dynamic components (Figs. 6a,c,g). Since horizontal temperature advection anomaly plays an important role in modulating the vertical motion based on the quasi-geostrophic omega equation (Wei et al. 2017), we further examine the spatial patterns of changes in horizontal temperature advection $\left(-\mathbf{V}_{h} \cdot \nabla_{h} T\right.$, where $\mathbf{V}_{h}$ is the horizontal vector wind, $T$ is the temperature, and $\nabla_{h}$ is the horizontal operator) at $500 \mathrm{hPa}$ (Fig. 8). In JRA-55 (Fig. 8a), the horizontal temperature advection shows significant warm anomalies over the western and eastern parts of Central Asia but cold anomalies over the middle part. The locations of anomalous warm (cool) advection correspond to those of anomalous ascending (descending) motion in Fig. 7c. This relationship between temperature advection trend and vertical velocity trend is found in both CAM5-All and CAM5-Nat. The spatial patterns of changes in horizontal temperature advection derived from JRA-55 resemble CAM5-All (Fig. 8b) better than CAM5-Nat (Fig. 8c), although CAM5-All misses the observed warm advection anomalies in some parts of eastern Central Asia. The warming trend of horizontal temperature advection in CAM5-All is mainly contributed by human influence (Fig. 8d).

In both JRA-55 and CAM5-Ant, the warm advection anomalies are dominated by meridional warm advection anomalies (Figs. 9a,b). This term is further divided into one component associated with changes in meridional wind (Figs. 9c,d) and one component associated with changes in air temperature (Figs. 9e,f). In JRA-55, the changes in meridional wind and temperature favor the warm advection anomalies over eastern and western Central Asia, respectively. In CAM5-Ant, changes in meridional wind favor the warm advection anomalies over the western and eastern parts of Central Asia, while changes in temperature favor the warm advection anomalies over western Central Asia. In both JRA-55 and CAM5-Ant, the contribution of changes in meridional wind is larger than that of the corresponding changes in temperature.

The trends of winds and temperature responsible for temperature advection trends are further examined, as shown in Fig. 10. Climatologically, the west and east parts of Central Asia in JRA-55 are dominated by northerly and southerly winds, respectively (contours in Fig. 10a). The anomalous southerlies are seen in JRA-55 for 1961-2013 (Fig. 10a, shading), bringing much more warm air from South to Central Asia, consistent with the temperature advection trends shown in Fig. 9c.

The temperature trends are distributed unevenly surrounding Central Asia, with a faster warming trend to the north of Central Asia, but cooling over southern Central Asia (Fig. 10g). This cooling trend has been reported by previous studies (Zhou and Zhang 2009; Zhou and Huang 2010; Zhao et al. 2014). Based on the "thermal wind" relationship, more warming over the high latitudes and cooling over Central Asia weakens the meridional temperature gradients to its north part 
(a) Omega_clm

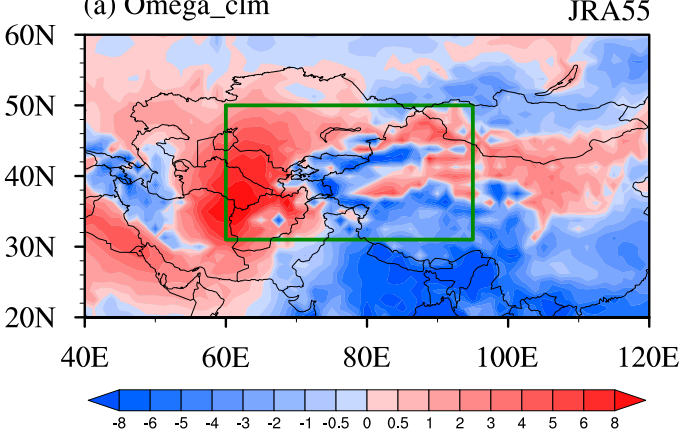

(c) Omega_trend

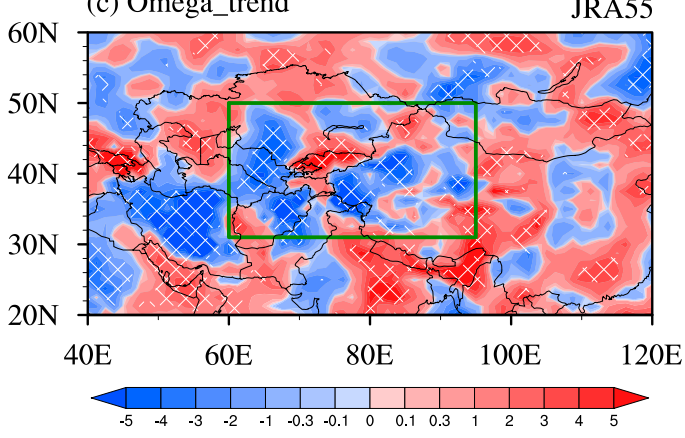

(e) Omega_trend

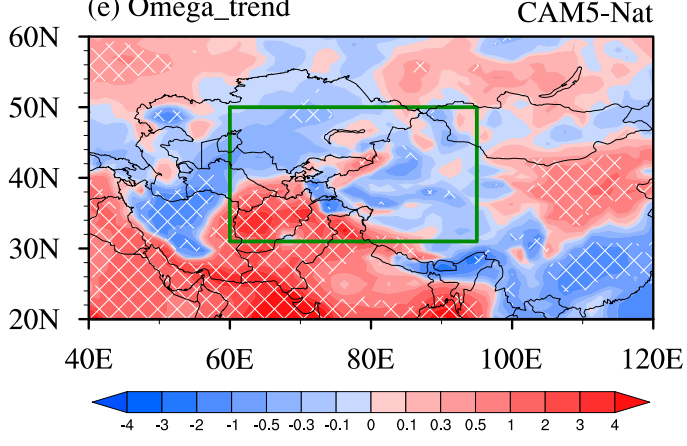

(b) Omega_clm

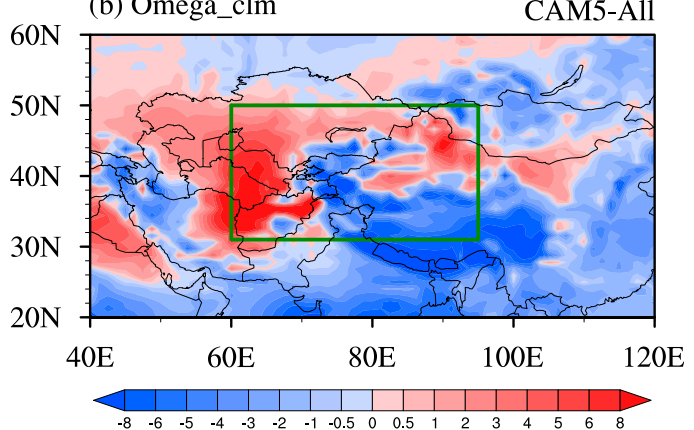

(d) Omega_trend

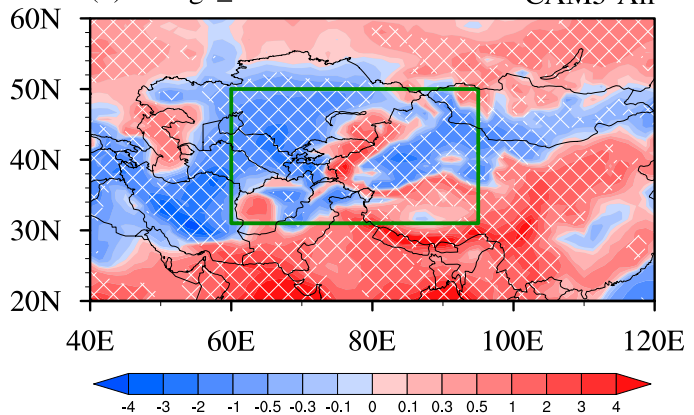

(f) Omega_trend

CAM5-Ant

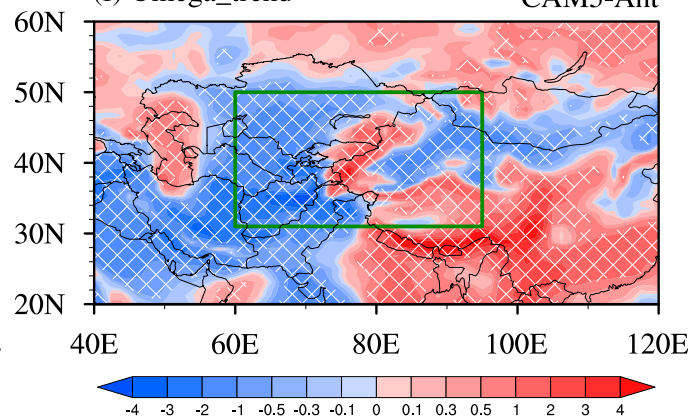

FIG. 7. The spatial patterns of summer mean vertical velocity at $500 \mathrm{hPa}$ during 1961-2013. (a),(b) The climatological mean $\left(10^{-2} \mathrm{~Pa} \mathrm{~s}^{-1}\right)$ for JRA-55 and CAM5-All, respectively. (c)-(f) The long-term trends $\left(10^{-3} \mathrm{~Pa} \mathrm{~s}^{-1} \mathrm{decade}^{-1}\right)$ from JRA-55, CAM5-All, CAM5-Nat, and CAM5-Ant, respectively.

but enhances those to the south, inducing the corresponding changes in geopotential height (Fig. 10e), thus leading to a weaker westerly over north Central Asia but a stronger westerly wind over south Central Asia (Fig. 10c). As a result, the subtropical westerly jet over Central Asia shifts southward, inducing an anomalous southerly wind over Central Asia and bring in more warm air (Fig. 9c). In addition, the uneven warming trends combined with the climatological northerly wind over western Central Asia benefit the warm advection trend (the component associated with changes in temperature), as shown in Fig. 9e.

The climatological distributions of meridional and zonal wind are well captured by CAM5.1 (the contours in Figs. 10b,d). In response to anthropogenic forcing, a significant warming trend is seen over the continent with a faster warming rate at higher-latitude regions (Fig. 10h), whereas the cooling trend over Central Asia in JRA-55 is absent in CAM5-Ant. Human-induced uneven warming results in the uneven changes in geopotential height (Fig. 10f), inducing an anomalous easterly and westerly winds over the northern and southern parts of western Central Asia, and an anomalous easterly wind over eastern Central Asia but with a relatively weaker magnitude in the south. As a result, the subtropical westerly jet over Central Asia shows a southward displacement (similar to the results in JRA55 but with smaller regions), inducing the anomalous 
(a) Temp. advec

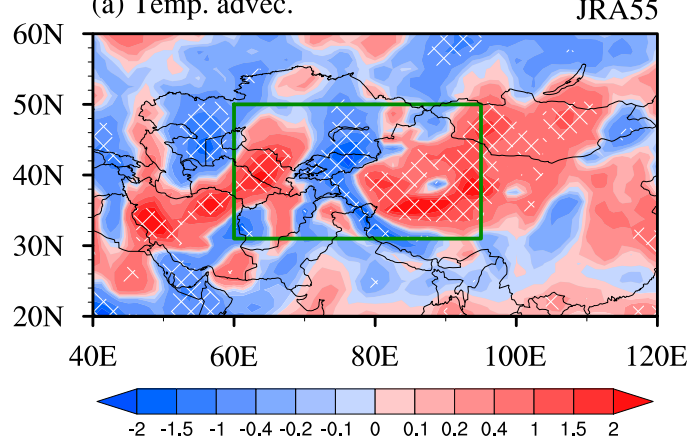

(c) Temp. advec.

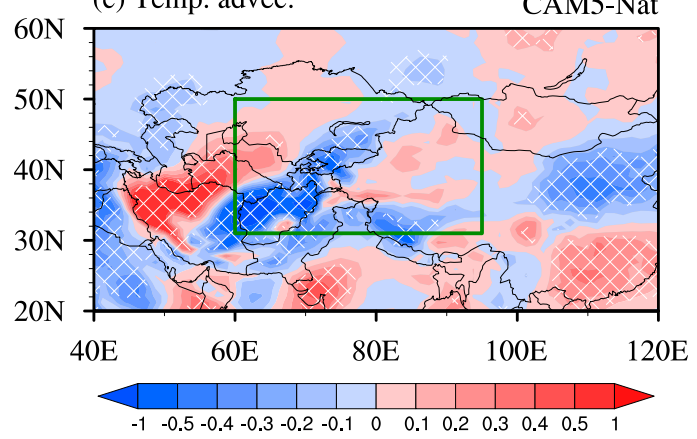

(b) Temp. advec.

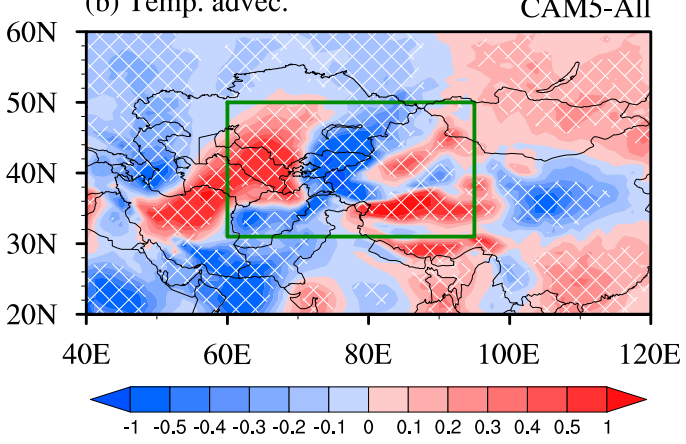

(d) Temp. advec.

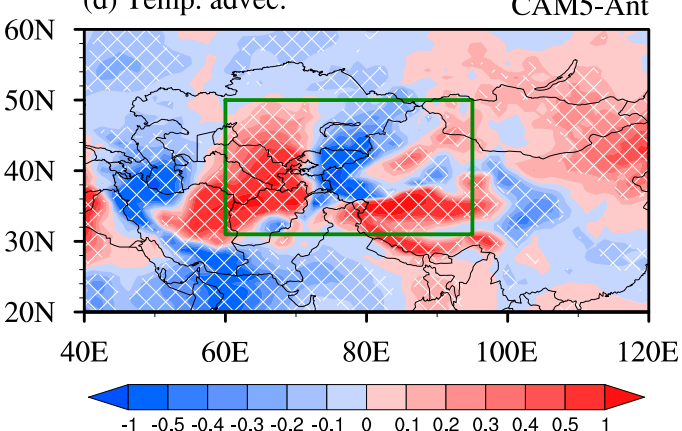

FIG. 8. Spatial patterns for the trend of horizontal temperature advection $\left(10^{-6} \mathrm{~K}^{-1} \mathrm{~s}^{-1} \mathrm{decade}^{-1}\right)$ at $500 \mathrm{hPa}$. (a) JRA-55; (b) CAM5-All; (c) CAM5-Nat; (d) CAM5-Ant.

southerly wind, which can bring more warm air. Combined with the faster warming rates at the high latitudes in CAM5-Ant, the climatological northerly wind over western Central Asia brings warm air to that region (Fig. 9f), consistent with the results of JRA-55. The warm advection anomalies favor anomalous ascending motion, thus resulting in more summer precipitation over Central Asia.

According to Eq. (2), the thermodynamic contribution is determined by the combination of specific humidity changes and the climatological vertical velocity. In response to global warming, the atmospheric moisture content increases and the global water cycle accelerates (Held and Soden 2006). Thus, human influence results in a uniform increasing trend of summer precipitable water in Central Asia (not shown). However, this uniform increasing pattern is different from the zonal dipole pattern of the thermodynamic term trend (Fig. 6b) because of the climatological distribution of vertical velocity [subsidence in western part and ascent in eastern part of Central Asia (Fig. 7b)]. As a result, human-induced increasing precipitable water contributes more precipitation in the climatological ascent region (eastern part of Central Asia), but reduces the precipitation in the climatological subsidence region (western part of Central Asia).

\section{Summary}

Analysis of existing observational datasets shows that the summer precipitation in Central Asia, an arid and semiarid region, has experienced a significant increasing trend during 1961-2013. However, whether this is a result of natural or anthropogenic change remains unknown. The thermodynamic and dynamical mechanisms behind the wetting trend also lack investigation. In this study, we compared the results derived from the observation and reanalysis with two sets of CAM5.1 attribution experiments-one driven by historical SST and radiative forcing (CAM5-All) and another forced only by natural radiative forcing and historical SST with anthropogenic influence removed (CAM5-Nat). The physical mechanisms behind the observed wetting trend and the role of anthropogenic influence in modulating these physical processes are examined. The results demonstrate that human activities have contributed significantly to the wetting trend of Central Asia from 1961 to 2013. The major findings are summarized below:

1) The average of four observed precipitation datasets, including the 75Station, PRECL, CRU, and GPCC data, shows that the summer precipitation in Central Asia has significantly increased by $20.78 \%$ from 1961 
(a) $-v \partial_{y} T$

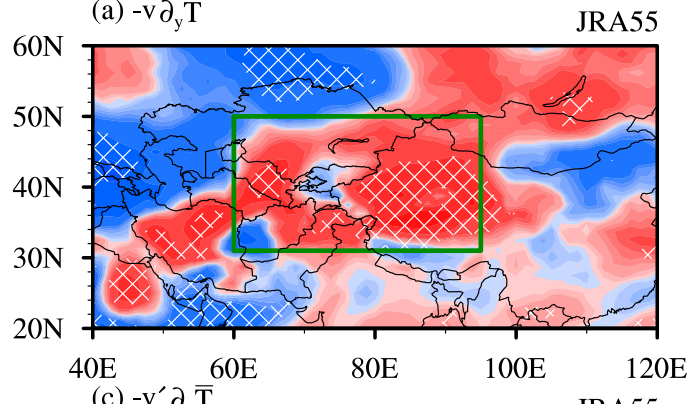

(b) $-\mathrm{v} \partial_{\mathrm{y}} \mathrm{T}$

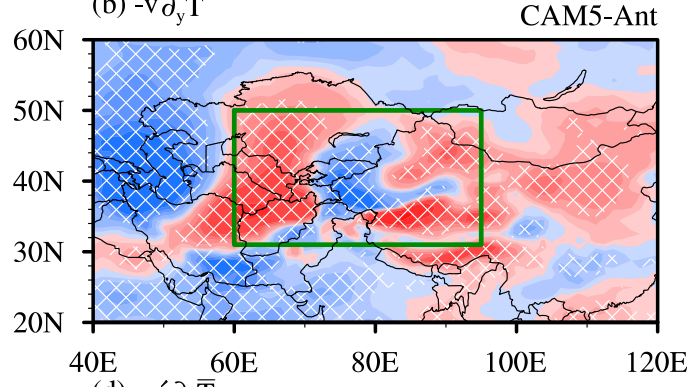

CAM5-Ant

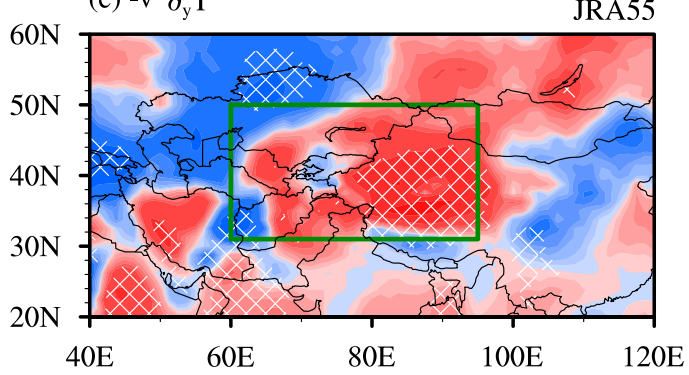

(e) $-\bar{v} \partial_{\mathrm{y}} \mathrm{T}^{\prime}$
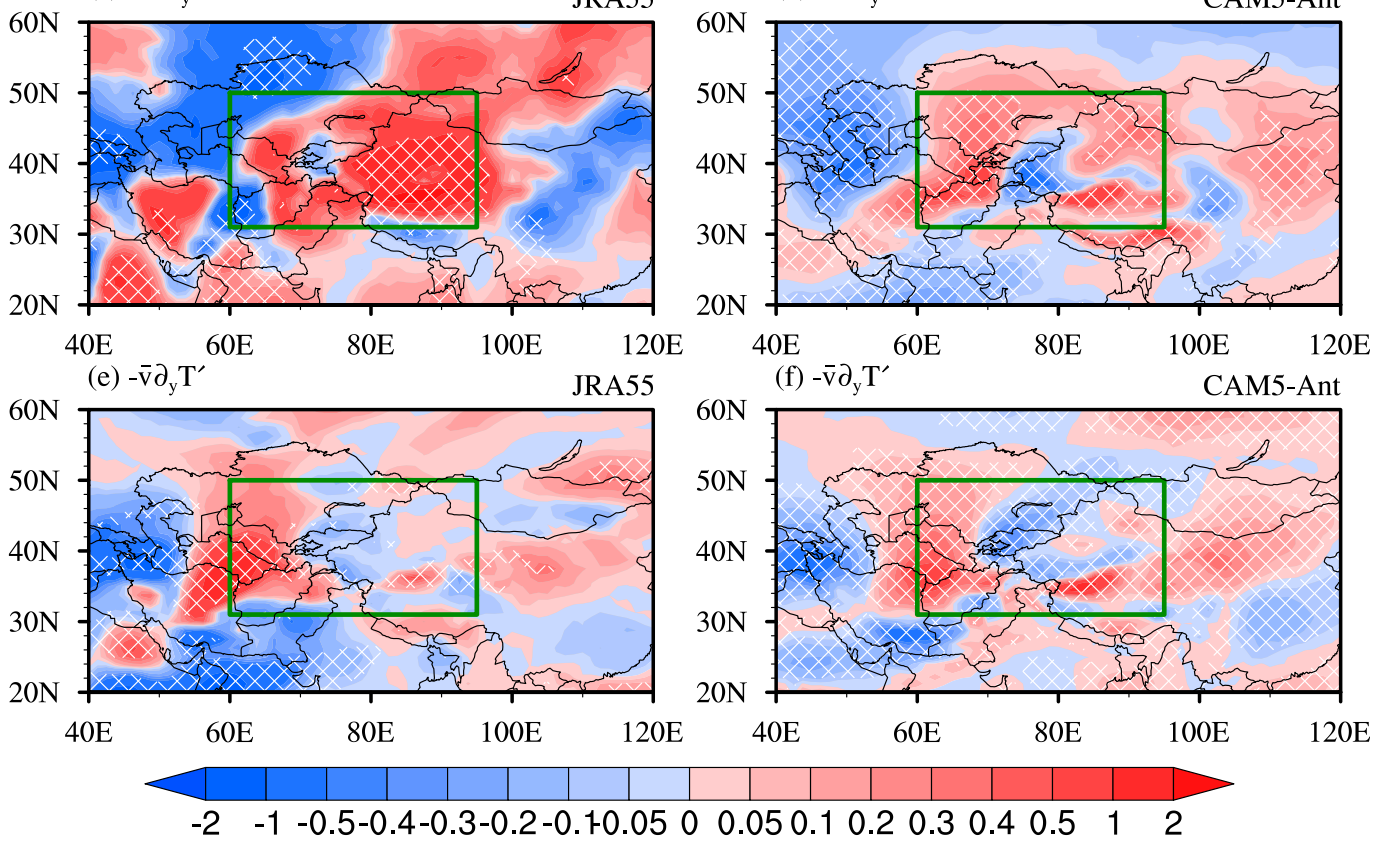

(f) $-\bar{v} \partial_{\mathrm{y}} \mathrm{T}^{\prime}$

CAM5-Ant

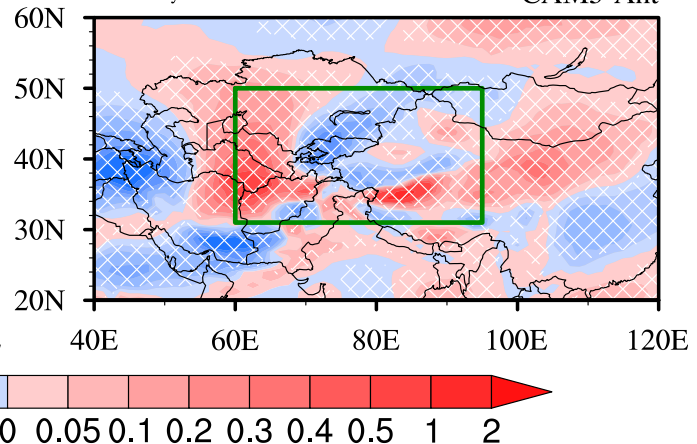

FIG. 9. Spatial patterns for the trend of meridional temperature advection components $\left(10^{-6} \mathrm{~K}^{-1} \mathrm{~s}^{-1} \mathrm{decade}^{-1}\right)$ at $500 \mathrm{hPa}$. (a),(b) the meridional temperature advection; (c),(d) the component associated with changes in meridional wind; (e),(f) the component associated with changes in temperature. (left) JRA-55 and (right) CAM5-Ant.

to 2013. The observed increasing precipitation trend over Central Asia is well captured by the CAM5-All, whereas the CAM5-Nat shows a drying trend. Thus, human influence has played an important role in the observed wetting trend and increased the summer precipitation by $17.72 \%$ in the past 50 years.

2) A moisture budget analysis based on JRA-55 indicates that the observed wetting trend is dominated by the changes in vertical moisture advection term. The changes in vertical moisture advection are further divided into dynamic components in association with changes in atmospheric circulation and thermodynamic components in association with changes in specific humidity. The dynamic contribution is a dominant contributor to the wetting trend and increases the precipitation over all of Central Asia, while the thermodynamic contribution increases (decreases) the precipitation over the eastern (western) part of Central Asia. The evaporation couples well with the precipitation and also shows a significant increasing trend, indicating a feedback between them. All the changes in moisture budget components responsible for the observed increasing precipitation are well captured by the CAM5-All, but these changes failed to be captured by the CAM5-Nat. Thus, the observed changes in moisture budget components in association with the wetting trend are mainly from human influence.

3) Human-induced dynamic contribution is the main contributor to the wetting trend over Central Asia, and the corresponding physical mechanisms are depicted in Fig. 11. In response to human influence, the temperature of the troposphere increases significantly over the Eurasian continent, with faster warming rates over the high latitudes, resulting in a meridional uneven warming pattern. It weakens the 
(a) V500

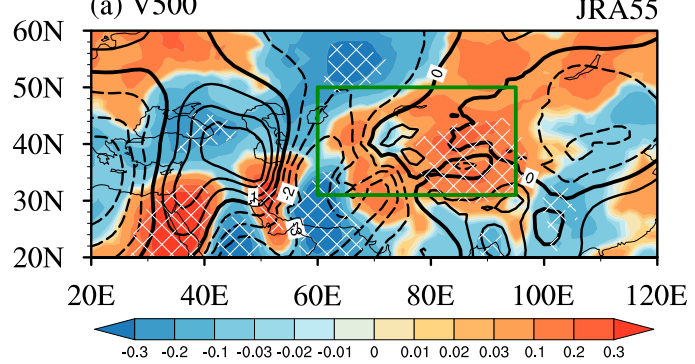

(c) U200

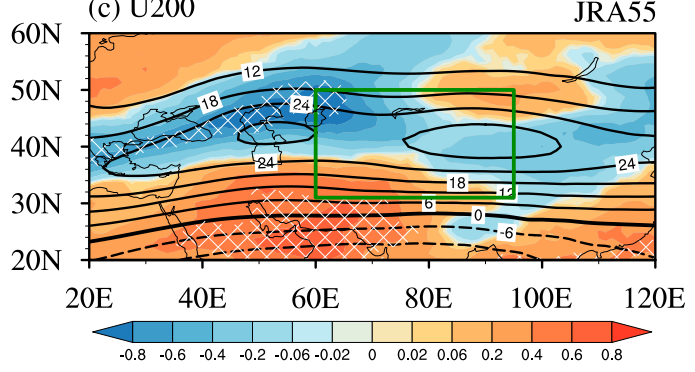

(e) Z200

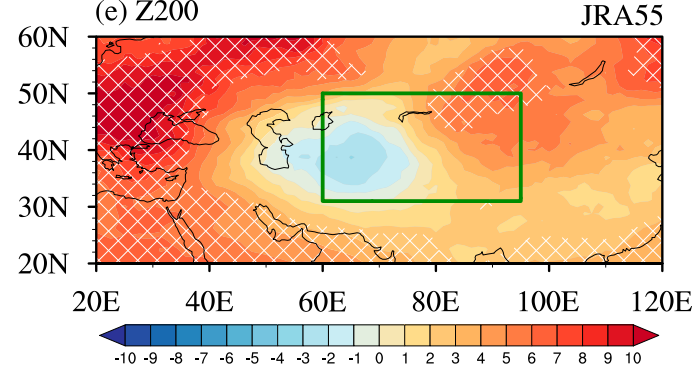

(g) Warming trend

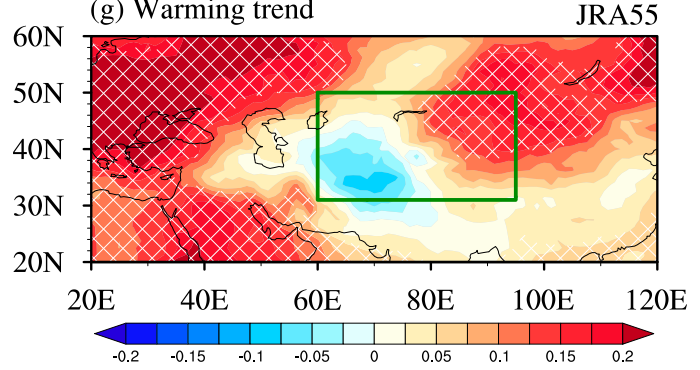

(b) V500

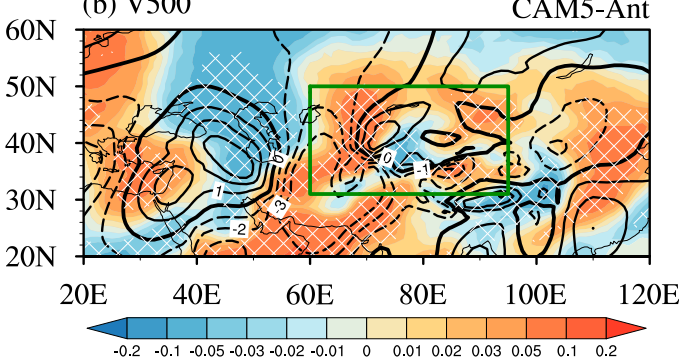

(d) U200

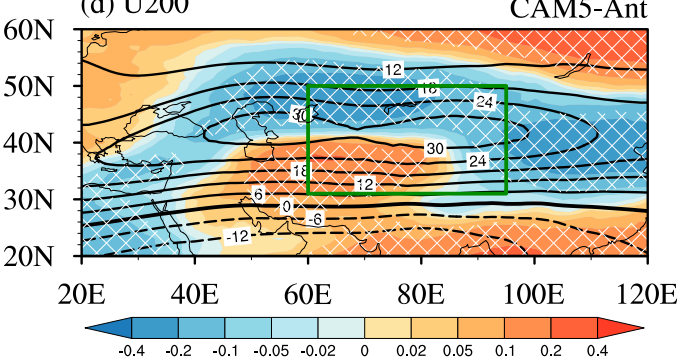

(f) Z200

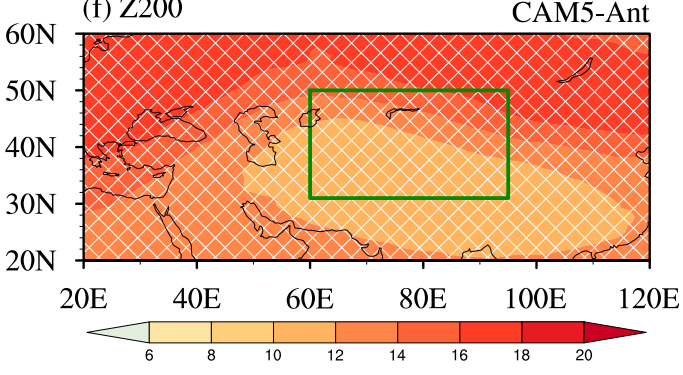

(h) Warming trend

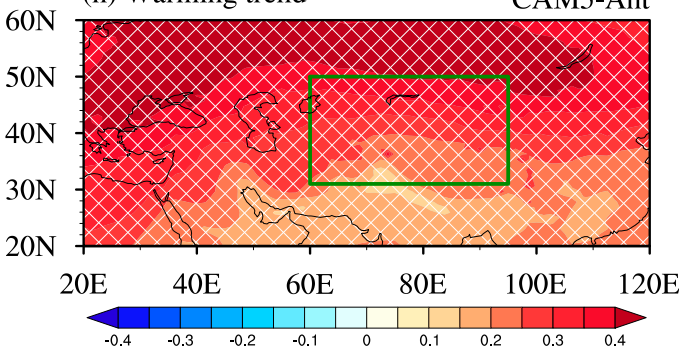

FIG. 10. (a),(b) Spatial patterns for the trend of meridional wind at $500 \mathrm{hPa}\left(\mathrm{m} \mathrm{s}^{-1} \mathrm{decade}^{-1}\right)$, (c), (d) zonal wind $\left(\mathrm{m} \mathrm{s}^{-1}\right.$ decade $\left.^{-1}\right)$, (e),(f) geopotential height at $200 \mathrm{hPa}\left(\mathrm{m} \mathrm{decade}^{-1}\right)$, and $(\mathrm{g}),(\mathrm{h})$ the temperature of the troposphere (from the surface to $200 \mathrm{hPa} ; \mathrm{K}$ decade $^{-1}$ ). The contours in (a)-(d) are the corresponding climatology $\left(\mathrm{m} \mathrm{s}^{-1}\right.$ ) of the meridional wind in (a) and (b) and the zonal wind in (c) and (d). Solid and dashed lines denote positive and negative values, and the thick solid lines indicate zero. (left) JRA-55 and (right) CAM5-Ant.

meridional thermal gradient over Central Asia and results in the southward displacement of the subtropical westerly jet over Central Asia, inducing an anomalous southerly wind over most parts of Central Asia and bringing in more warm air. Meanwhile, combined with the climatological northerly wind over western Central Asia, the larger warming rate at higher latitudes also favors stronger warm advection over western Central Asia. As a result of stronger warm advection over Central Asia, an anomalous ascending motion is simulated in CAM5-Ant, increasing the summer precipitation. A feedback is seen between increased precipitation and evaporation. We note human-induced warming increases the atmospheric moisture content over all of Central Asia, and favors more precipitation over the eastern part of Central Asia (the climatological ascent regions), while decreasing the precipitation over the 


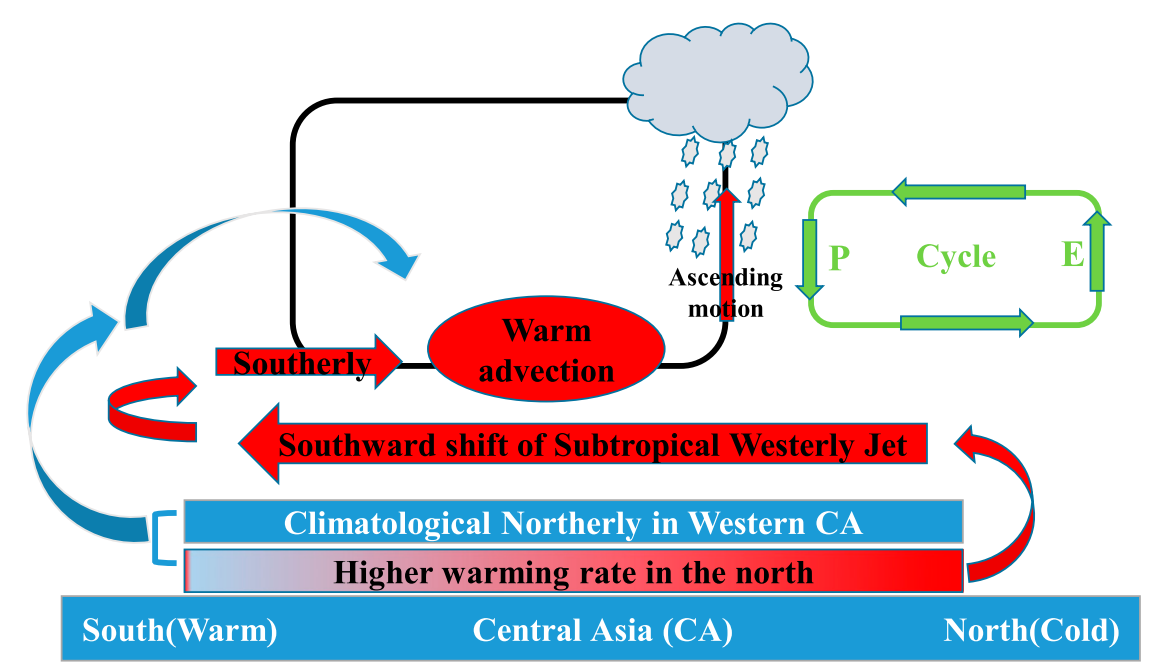

FIG. 11. Schematic diagram of the physical mechanisms responsible for the human-induced summer wetting trend over Central Asia. Blue indicates the climatological background, and red indicates the changes in response to human influence. The increasing trend is dominated by warm advection anomalies-induced anomalous ascending motion in response to the uneven warming. The warm advection anomalies are dominated by the southward movement of the subtropical westerly jet, followed by the climatological northerly wind in western Central Asia. There is a feedback between the increased evaporation $E$ and precipitation $P$ (green).

western part of Central Asia (the climatological subsidence regions).

Although the natural radiative forcing is not larger with respect to human influence, a significant drying trend is found in CAM5-Nat. We note that the results of CAM5-Nat experiments are driven by both natural radiative forcing and natural SST variability. Further analyses indicate that the drying trend in CAM5-Nat is driven by the natural SST variability of the interdecadal Pacific oscillation (IPO). In CAM5-Nat, the precipitation over Central Asia shows a significant negative-correlation relationship (with a correlation coefficient of -0.44 after a 5-yr low-pass filter, significant at the 5\% level) with the tripole index (TPI) for the IPO defined by Henley et al. (2015), with the strongest signal in the North Pacific Ocean (figures not shown). The upward trend of precipitation after 1992 is associated with the decrease of TPI in the CAM5.1 model. Note the decrease of TPI is also seen in the observations. The influence of IPO on atmospheric circulation over Central Asia has been illustrated by Watanabe and Yamazaki (2014); that is, there is a stationary wave train along the subtropical westerly jet associated with IPO, with an anomalous anticyclone (cyclone) over Central Asia associated with cool (warm) SST anomalies in the North Pacific Ocean.

This study shows evidence that the increasing summer precipitation over Central Asia is modulated by human influence, which is mainly because of human-induced global warming. The aerosol forcing, which is a dominant factor responsible for the Asian monsoon precipitation changes relative to the greenhouse gas (GHG) warming during past centuries ( $\mathrm{Li}$ et al. 2015, 2018), may also contribute to the wetting trend in Central Asia because it can influence the meridional displacement of the subtropical westerly jet (Song et al. 2014) which is associated with precipitation changes over Central Asia (Zhao et al. 2014; Peng and Zhou 2017). Because of the experimental design, the influence of climate warming and aerosol effect cannot be identified separately in this study by using the $\mathrm{C} 20 \mathrm{C}+$ Detection and Attribution experiments. To clearly reveal the relative contribution of different external forcing (such as aerosol, greenhouse gas, and land cover) in the precipitation changes over Central Asia, further studies are needed by designing specific numerical experiments that can separate the influences of GHG and aerosols under the umbrella of $\mathrm{C} 20 \mathrm{C}+$ projects.

Acknowledgments. This work is jointly supported by National Natural Science Foundation of China under Grant 41330423 and the Chinese Academy of Sciences. Lixia Zhang is supported by Ministry of Science and Technology of China under Grant 2018YFA0606500. Tianjun Zhou is also supported by the Jiangsu Collaborative Innovation Center for Climate Change. The CAM5.1 simulations used in the paper are provided by the subproject of the World Climate Research Programme's (WCRP) Climate Variability Programme's (CLIVAR) Climate of the 20th Century Plus (C20C + ) 
Project and can be directly accessed from http://portal. nersc.gov/c20c/data.html.

\section{REFERENCES}

Allen, M. R., and W. J. Ingram, 2002: Constraints on future changes in climate and the hydrologic cycle. Nature, 419, 224-232, https://doi.org/10.1038/nature01092.

Allen, R. G., L. S. Pereira, D. Raes, and M. Smith, 1998: Crop evapotranspiration: Guidelines for computing crop water requirements. FAO Irrigation and Drainage Paper 56, 300 pp., www.fao.org/docrep/X0490E/X0490E00.htm.

Angélil, O., D. Stone, M. Wehner, C. J. Paciorek, H. Krishnan, and W. Collins, 2017: An independent assessment of anthropogenic attribution statements for recent extreme temperature and rainfall events. J. Climate, 30, 5-16, https://doi.org/ 10.1175/JCLI-D-16-0077.1.

Bhend, J., and H. Von Storch, 2008: Consistency of observed winter precipitation trends in northern Europe with regional climate change projections. Climate Dyn., 31, 17-28, https://doi.org/ 10.1007/s00382-007-0335-9.

Bollasina, M. A., Y. Ming, and V. Ramaswamy, 2011: Anthropogenic aerosols and the weakening of the South Asian summer monsoon. Science, 334, 502-505, https://doi.org/10.1126/science.1204994.

Chen, M. Y., P. Xie, J. E. Janowiak, and P. A. Arkin, 2002: Global land precipitation: A 50-yr monthly analysis based on gauge observations. J. Hydrometeor., 3, 249-266, https://doi.org/ 10.1175/1525-7541(2002)003<0249:GLPAYM > 2.0.CO;2.

Chou, C., and C.-W. Lan, 2012: Changes in the annual range of precipitation under global warming. J. Climate, 25, 222-235, https://doi.org/10.1175/JCLI-D-11-00097.1.

_ J. C. H. Chiang, C.-W. Lan, C.-H. Chung, Y.-C. Liao, and C.-J. Lee, 2013: Increase in the range between wet and dry season precipitation. Nat. Geosci., 6, 263-267 https://doi.org/ 10.1038/ngeo1744.

Delworth, T. L., and F. Zeng, 2014: Regional rainfall decline in Australia attributed to anthropogenic greenhouse gases and ozone levels. Nat. Geosci., 7, 583-587, https://doi.org/10.1038/ngeo2201.

Ding, Q., and B. Wang, 2005: Circumglobal teleconnection in the Northern Hemisphere summer. J. Climate, 18, 3483-3505, https://doi.org/10.1175/JCLI3473.1.

Folland, C., D. Stone, C. Frederiksen, D. Karoly, and J. Kinter, 2014: The International CLIVAR Climate of the 20th Century Plus $(\mathrm{C} 20 \mathrm{C}+)$ Project: Report of the sixth workshop. CLIVAR Exchanges, No. 19, International CLIVAR Project Office, Southampton, United Kingdom, 57-59.

Gillett, N. P., A. J. Weaver, F. W. Zwiers, and M. F. Wehner, 2004: Detection of volcanic influence on global precipitation. Geophys. Res. Lett., 31, L12217, https://doi.org/10.1029/ 2004GL020044.

Harris, I. C., and P. D. Jones, 2017: CRU TS4.00: Climatic Research Unit (CRU) Time-Series (TS) version 4.00 of highresolution gridded data of month-by-month variation in climate (Jan. 1901-Dec. 2015). Centre for Environmental Data Analysis, accessed 25 May 2017, https://doi.org/10.5285/ edf8febfdaad48abb2cbaf7d7e846a86.

Hegerl, G., and F. W. Zwiers, 2011: Use of models in detection and attribution of climate change. Wiley Interdiscip. Rev.: Climate Change, 2, 570-591, https://doi.org/10.1002/wcc.121.

Held, I. M., and B. J. Soden, 2006: Robust responses of the hydrological cycle to global warming. J. Climate, 19, 5686-5699, https://doi.org/10.1175/JCLI3990.1.
Henley, B. J., J. Gergis, D. J. Karoly, S. Power, J. Kennedy, and C. K. Folland, 2015: A tripole index for the interdecadal Pacific oscillation. Climate Dyn., 45, 3077-3090, https://doi.org/ 10.1007/s00382-015-2525-1.

$\mathrm{Hu}$, Z., Q. Zhou, X. Chen, Q. Cheng, S. Wang, and J. Li, 2017: Variations and changes of annual precipitation in Central Asia over the last century. Int. J. Climatol., 37, 157-170, https:// doi.org/10.1002/joc.4988.

Huang, J. P., M. Ji, Y. K. Xie, S. Wang, Y. He, and J. Ran, 2016: Global semi-arid climate change over last 60 years. Climate Dyn., 46, 1131-1150, https://doi.org/10.1007/s00382-015-2636-8.

— , H. P. Yu, A. Dai, and L. T. Kang, 2017: Drylands face potential threat under $2^{\circ} \mathrm{C}$ global warming target. Nat. Climate Change, 7, 417-422, https://doi.org/10.1038/nclimate3275.

Huang, W., J. H. Chen, X. Zhang, S. Feng, and F. Chen, 2015a: Definition of the core zone of the "westerlies-dominated climatic regime", and its controlling factors during the instrumental period. Sci. China Earth Sci., 58, 676-684, https:// doi.org/10.1007/s11430-015-5057-y.

- S. Feng, J. H. Chen, and F. Chen, 2015b: Physical mechanisms of summer precipitation variations in the Tarim basin in northwestern China. J. Climate, 28, 3579-3591, https://doi.org/ 10.1175/JCLI-D-14-00395.1.

IPCC, 2013: Climate Change 2013: The Physical Science Basis. Cambridge University Press, 1535 pp., https://doi.org/10.1017/ CBO9781107415324.

Knutson, T. R., F. Zeng, and A. T. Wittenberg, 2013: Multimodel assessment of regional surface temperature trends: CMIP3 and CMIP5 twentieth-century simulations. J. Climate, 26, 8709-8743, https://doi.org/10.1175/JCLI-D-12-00567.1.

Kobayashi, S., and Coauthors, 2015: The JRA-55 Reanalysis: General specifications and basic characteristics. J. Meteor. Soc. Japan, 93, 5-48, https://doi.org/10.2151/jmsj.2015-001.

Lambert, F. H., P. A. Stott, M. R. Allen, and M. A. Palmer, 2004: Detection and attribution of changes in 20th century land precipitation. Geophys. Res. Lett., 31, L10203, https://doi.org/ 10.1029/2004GL019545.

Li, B., Y. N. Chen, Z. S. Chen, H. G. Xiong, and L. S. Lian, 2016: Why does precipitation in northwest China show a significant increasing trend from 1960 to 2010? Atmos. Res., 167, 275-284, https://doi.org/10.1016/j.atmosres.2015.08.017.

Li, X., M. Ting, C. Li, and N. Henderson, 2015: Mechanisms of Asian summer monsoon changes in response to anthropogenic forcing in CMIP5 models. J. Climate, 28, 4107-4125, https:// doi.org/10.1175/JCLI-D-14-00559.1.

,$- \ldots$, and D. E. Lee, 2018: Fast adjustments of the Asian summer monsoon to anthropogenic aerosols. Geophys. Res. Lett., 45, 1001-1010, https://doi.org/10.1002/2017GL076667.

Ma, S., T. Zhou, A. Dai, and Z. Han, 2015: Observed changes in the distributions of daily precipitation frequency and amount over China from 1960 to 2013. J. Climate, 28, 6960-6978, https:// doi.org/10.1175/JCLI-D-15-0011.1.

,-- D. A. Stone, O. Angélil, and H. Shiogama, 2017a: Attribution of the July-August 2013 heat event in central and eastern China to anthropogenic greenhouse gas emissions. Environ. Res. Lett., 12, 054020, https://doi.org/10.1088/1748-9326/ aa69d2.

— ward heavy precipitation over eastern China. J. Climate, 30, 1381-1396, https://doi.org/10.1175/JCLI-D-16-0311.1.

Mariotti, A., 2007: How ENSO impacts precipitation in southwest Central Asia. Geophys. Res. Lett., 34, L16706, https://doi.org/ 10.1029/2007GL030078. 
Min, S. K., X. B. Zhang, and F. W. Zwiers, 2008: Human-induced Arctic moistening. Science, 320, 518-520, https://doi.org/10.1126/ science. 1153468.

,,,--- and G. C. Hegerl, 2011: Human contribution to more-intense precipitation extremes. Nature, 470, 378-381, https://doi.org/10.1038/nature09763.

Noake, K., D. Polson, G. Hegerl, and X. Zhang, 2012: Changes in seasonal land precipitation during the latter twentiethcentury. Geophys. Res. Lett., 39, L03706, https://doi.org/10.1029/ 2011GL050405.

Peng, D., and T. Zhou, 2017: Why was the arid and semiarid northwest China getting wetter in the recent decades? J. Geophys. Res. Atmos., 122, 9060-9075, https://doi.org/10.1002/ 2016JD026424.

Polson, D., G. C. Hegerl, X. B. Zhang, and T. J. Osborn, 2013: Causes of robust seasonal land precipitation changes. J. Climate, 26, 6679-6697, https://doi.org/10.1175/JCLI-D-12-00474.1.

Sarojini, B. B., P. A. Stott, and E. Black, 2016: Detection and attribution of human influence on regional precipitation. Nat. Climate Change, 6, 669-675, https://doi.org/10.1038/ nclimate2976.

Schneider, U., A. Becker, P. Finger, A. Meyer-Christoffer, B. Rudolf, and M. Ziese, 2015: GPCC full data reanalysis version 7.0 at $0.5^{\circ}$ : Monthly land-surface precipitation from rain-gauges built on GTS-based and historic data. GPCC, accessed 1 July 2017, https://doi.org/10.5676/DWD_GPCC/FD_M_V7_050.

Seager, R., N. Naik, and G. A. Vecchi, 2010: Thermodynamic and dynamic mechanisms for large-scale changes in the hydrological cycle in response to global warming. J. Climate, 23 , 4651-4668, https://doi.org/10.1175/2010JCLI3655.1.

Shi, Y. F., Y. P. Shen, E. Kang, D. L. Li, Y. J. Ding, G. W. Zhang, and R. J. Hu, 2007: Recent and future climate change in northwest China. Climatic Change, 80, 379-393, https:// doi.org/10.1007/s10584-006-9121-7.

Song, F., T. Zhou, and Y. Qian, 2014: Responses of East Asian summer monsoon to natural and anthropogenic forcings in the 17 latest CMIP5 models. Geophys. Res. Lett., 41, 596-603, https://doi.org/10.1002/2013GL058705.

Stone, D. A., and Coauthors, 2018: A basis set for exploration of sensitivity to prescribed ocean conditions for estimating human contributions to extreme weather in CAM5.1-1degree. Wea. Climate Extremes, 19, 10-19, https://doi.org/10.1016/ j.wace.2017.12.003.

Stott, P. A., N. P. Gillett, G. C. Hegerl, D. J. Karoly, D. A. Stone, X. Zhang, and F. Zwiers, 2010: Detection and attribution of climate change: A regional perspective. Wiley Interdiscip. Rev.: Climate Change, 1, 192-211, https://doi.org/10.1002/wcc.34.

Wan, H., X. B. Zhang, F. W. Zwiers, and S. K. Min, 2015: Attributing northern high-latitude precipitation change over the period 1966-2005 to human influence. Climate Dyn., 45, 17131726, https://doi.org/10.1007/s00382-014-2423-y.

Watanabe, T., and K. Yamazaki, 2014: Decadal-scale variation of South Asian summer monsoon onset and its relationship with the Pacific decadal oscillation. J. Climate, 27, 5163-5173, https://doi.org/10.1175/JCLI-D-13-00541.1.

Wei, W., R. Zhang, M. Wen, and S. Yang, 2017: Relationship between the Asian westerly jet stream and summer rainfall over Central Asia and north China: Roles of the Indian monsoon and the South Asian high. J. Climate, 30, 537-552, https:// doi.org/10.1175/JCLI-D-15-0814.1.

Zhang, X. B., F. W. Zwiers, G. C. C. Hegerl, F. H. Lambert, N. P. Gillett, S. Solomon, P. A. Stott, and T. Nozawa, 2007: Detection of human influence on twentieth-century precipitation trends. Nature, 448, https://doi.org/10.1038/nature06025.

— , H. Wan, F. W. Zwiers, G. C. C. Hegerl, and S. K. Min, 2013: Attributing intensification of precipitation extremes to human influence. Geophys. Res. Lett., 40, 5252-5257, https://doi.org/ 10.1002/grl.51010.

Zhao, Y., A. Huang, Y. Zhou, D. Huang, Q. Yang, Y. Ma, M. Li, and G. Wei, 2014: Impact of the middle and upper tropospheric cooling over Central Asia on the summer rainfall in the Tarim basin, China. J. Climate, 27, 4721-4732, https:// doi.org/10.1175/JCLI-D-13-00456.1.

Zhou, L. T., and R. H. Huang, 2010: Interdecadal variability of summer rainfall in northwest China and its possible causes. Int. J. Climatol., 30, 549-557, https://doi.org/10.1002/joc.1923.

Zhou, T., and J. Zhang, 2009: Harmonious inter-decadal changes of July-August upper tropospheric temperature across the North Atlantic, Eurasian continent, and North Pacific. Adv. Atmos. Sci., 26, 656-665, https://doi.org/10.1007/s00376-009-9020-8. 